University of Nebraska - Lincoln

DigitalCommons@University of Nebraska - Lincoln

USDA Wildlife Services - Staff Publications

U.S. Department of Agriculture: Animal and

Plant Health Inspection Service

2022

\title{
Plague risk in the western United States over seven decades of environmental change
}

Colin J. Carlson

Sarah N. Bevins

Boris V. Schmid

Follow this and additional works at: https://digitalcommons.unl.edu/icwdm_usdanwrc

Part of the Natural Resources and Conservation Commons, Natural Resources Management and Policy Commons, Other Environmental Sciences Commons, Other Veterinary Medicine Commons, Population Biology Commons, Terrestrial and Aquatic Ecology Commons, Veterinary Infectious Diseases Commons, Veterinary Microbiology and Immunobiology Commons, Veterinary Preventive Medicine, Epidemiology, and Public Health Commons, and the Zoology Commons

This Article is brought to you for free and open access by the U.S. Department of Agriculture: Animal and Plant Health Inspection Service at DigitalCommons@University of Nebraska - Lincoln. It has been accepted for inclusion in USDA Wildlife Services - Staff Publications by an authorized administrator of DigitalCommons@University of Nebraska - Lincoln. 


\title{
Plague risk in the western United States over seven decades of environmental change
}

\author{
Colin J. Carlson $^{1}$ (1) | Sarah N. Bevins ${ }^{2}$ | Boris V. Schmid ${ }^{3}$
}

${ }^{1}$ Center for Global Health Science and Security, Georgetown University Medical Center, Washington, District of Columbia, USA

${ }^{2}$ US Department of Agriculture Animal and Plant Health Inspection Service-Wildlife Services National Wildlife Research Center, Fort Collins, Colorado, USA

${ }^{3}$ Centre for Ecological and Evolutionary Synthesis, Department of Biosciences, University of Oslo, Oslo, Norway

\section{Correspondence}

Colin J. Carlson, Center for Global Health Science and Security, Georgetown University Medical Center, Washington, D.C. 20057, USA.

Email: colin.carlson@georgetown.edu

Funding information

Research Council of Norway, Grant/Award Number: FRIMEDBIO project288551

\begin{abstract}
After several pandemics over the last two millennia, the wildlife reservoirs of plague (Yersinia pestis) now persist around the world, including in the western United States. Routine surveillance in this region has generated comprehensive records of human cases and animal seroprevalence, creating a unique opportunity to test how plague reservoirs are responding to environmental change. Here, we test whether animal and human data suggest that plague reservoirs and spillover risk have shifted since 1950. To do so, we develop a new method for detecting the impact of climate change on infectious disease distributions, capable of disentangling long-term trends (signal) and interannual variation in both weather and sampling (noise). We find that plague foci are associated with high-elevation rodent communities, and soil biochemistry may play a key role in the geography of long-term persistence. In addition, we find that human cases are concentrated only in a small subset of endemic areas, and that spillover events are driven by higher rodent species richness (the amplification hypothesis) and climatic anomalies (the trophic cascade hypothesis). Using our detection model, we find that due to the changing climate, rodent communities at high elevations have become more conducive to the establishment of plague reservoirs-with suitability increasing up to $40 \%$ in some places-and that spillover risk to humans at mid-elevations has increased as well, although more gradually. These results highlight opportunities for deeper investigation of plague ecology, the value of integrative surveillance for infectious disease geography, and the need for further research into ongoing climate change impacts.
\end{abstract}

\section{KEYWORDS}

Bayesian additive regression trees, climate change, ecological niche modeling, plague, Yersinia pestis

\section{1 | INTRODUCTION}

The distribution and burden of infectious diseases will be entirely reshaped by global environmental change. Scientific consensus suggests that over the next century, the combined effect of climate change, land degradation and transformation, and increasing human-wildlife contact will bring about a massive increase in the spillover of pathogens that originate in wildlife (zoonotic diseases) 
(Carlson et al., 2020; Estrada-Pena et al., 2014) and the burden of infections transmitted by arthropods (vector-borne diseases) (Caminade et al., 2019; Rocklöv \& Dubrow, 2020). While there are substantial research efforts working to project these future changes (Carlson et al., 2020; Kraemer et al., 2019; Ryan et al., 2019), the impacts of current environmental change on infectious disease burden in the world today are underexplored. Based on current evidence, land use change is the best-supported leading driver of zoonotic emergence (Gibb et al., 2020; Loh et al., 2015); much less is known about climate change impacts to date. This is due, in large part, to methodological limitations: the "detection and attribution" methods that are best suited to this problem require substantial data on disease prevalence or incidence over extensive periods, as well as complicated model designs (e.g., counterfactual climate scenarios without climate change) (Carleton \& Hsiang, 2016; Ebi et al., 2017).

Instead, many projections of climate change impacts rely on ecological niche models (also known as species distribution models), a set of regression and machine learning approaches that relate climate to the geographic range of a species (Escobar \& Craft, 2016; Hay et al., 2013). Usually, these approaches are an oversimplification of reality, especially for pathogens: for example, a map of anthrax (Bacillus anthracis) may classify west Texas as an endemic zone, even though the system is characterized by epizootics that are sometimes years apart (Blackburn et al., 2007). Ecological niche models are therefore an imperfect tool for exploring climate change impacts. These methods work well for mapping current distributions, for projecting singletime-slice distributions under future climates, and-in some recent work-for projecting continuous-time change (Trisos et al., 2020). Retrospective work to reconstruct climate change impacts is much rarer, and is usually restricted to work that builds two species distribution models for contrasting time intervals and compares them (Dobrowski et al., 2011; Kulkarni et al., 2016; Nakazawa et al., 2007). This approach is less than ideal, forcing researchers to violate the assumption that species' geographic ranges are at equilibrium (Araújo et al., 2005; Gallien et al., 2012); to aggregate data into somewhat arbitrary time periods; and to compare models trained on nonindependent but nonoverlapping datasets, which will generate different biological response curves simply because of model uncertainty. In this framework, it is also difficult to eliminate alternate hypotheses for why a species' apparent distribution might change, like noise in the detection process or shifting abundance patterns.

Recently, a growing set of tools have tried to grapple with the temporal variability exhibited by the distribution of infectious diseases. Though most disease maps are treated as the long-term average of temporally dynamic processes, time-specific ecological niche modeling has been proposed as an alternative that captures the dynamic nature of transmission. Almost always, though, these methods have been implemented at the finest temporal scales: monthly (Peterson et al., 2005) or seasonal (Kaul et al., 2018; Schmidt et al., 2017). Yet, this approach has been mostly untested as a way of understanding disease distributions over multiple years-and, ideally, of contextualizing the impacts of environmental change over decades (but see Nakazawa et al. (2007)).
Few systems provide a better opportunity to test this approach than plague, a globally cosmopolitan zoonotic infection caused by the bacterium Yersinia pestis. The bacterium is typically maintained by rodent (and sometimes shrew) hosts and the fleas that live on them or in their nests (Anisimov et al., 2004; Krasnov et al., 2006; Mahmoudi et al., 2020). Suitable plague reservoir host species are often thought to exhibit a standing variation in their susceptibility to the bacterium, such that some hosts generate a high enough (and often lethal) bacteremia in the blood for the efficient transmission of the bacterium by flea vectors, while the host population as a whole survives (Anisimov et al., 2004; Lowell et al., 2015; Nilsson et al., 2021). Which local flea species are important for the spread and persistence of the pathogen depends on their typical host's abundance, and the taxonomic range of hosts that they feed upon; both of these factors are correlated with intrinsic variation in their vector competence (Krasnov et al., 2006), and have important implications for plague dynamics, including spillover risk for humans. While other transmission modes are sometimes relevant to both spillover and epidemic transmission, including consumption of infected meat (Malek et al., 2016) and droplet transmission (Randremanana et al., 2019), respectively, the relationship between rodents, fleas, and bacteria gives shape to most salient ecological questions.

The global distribution of plague has been far from stable over the past two centuries; the Third Pandemic (late 18th to mid-20th Century) (Bramanti et al., 2019; Jones et al., 2019; Neerinckx et al., 2010a; Seal, 1960; Xu et al., 2014) in particular was responsible for the introduction of $Y$. pestis into many new regions that were environmentally suitable but otherwise uncolonized, particularly the Americas (Link, 1955; Morelli et al., 2010; Schneider et al., 2014). In some of these regions, outbreaks have faded over time, while in others, plague foci have persisted and the pathogen has become endemic, maintained by a sylvatic cycle in rodent reservoirs and flea vectors (Schneider et al., 2014). Rodent biodiversity hotspots may be particularly conducive to the formation of these reservoirs (Sun et al., 2019), a possible case of biodiversity amplification effects (Halliday \& Rohr, 2019; Luis et al., 2018), where the diversity of competent hosts allows a virulent pathogen to be maintained at more stable levels. Though underexplored, emerging evidence also suggests that plague may persist in the soil, possibly by acting as an endosymbiont with amoebas (Benavides-Montaño \& Vadyvaloo, 2017), from which it sporadically can reinfect burrowing rodents (Boegler et al., 2012). Soil conditions may therefore further constrain the distribution of plague reservoirs (Ayyadurai et al., 2008; Baltazard et al., 1964; Eisen et al., 2008; Karimi, 1963). Like other pathogens that can persist in the soil (Carlson et al., 2019; Limmathurotsakul et al., 2016), provisionary evidence suggests that plague may be limited by soil salinity (Barbieri et al., 2020; Malek et al., 2017), soil organic carbon, and alkalinity (Neerinckx et al., 2008). Though these factors may have limited influence in the short-term dynamics of plague in any one location, at continental scales, they could reasonably be expected to shape where plague foci have become established.

Both experimental and ecological analyses suggest that plague dynamics are also highly sensitive to climatic conditions. The disease's 
sensitivity to bioclimatic conditions has been documented throughout its life cycle, but is particularly pronounced on the arthropod level, where temperature (and to a lesser degree humidity) influence the rate at which various flea species move through their life cycle (Bacot, 1914). Flea species differ in their temperature sensitivities (Bacot, 1914), making the local composition of flea communities an important consideration. Temperature also directly influences biochemical aspects of the transmission efficiency of the plague bacterium, particularly when temperatures rise above $27^{\circ} \mathrm{C}$ (Eisen et al., 2009), presumably by negatively influencing the stability of the biofilm that the bacterium forms in fleas. Temperature also influences rodent populations, including through a mechanism generally referred to as a trophic cascade: climatic anomalies influence primary productivity, driving changes in rodent density, which in turn change the density and biting preferences of fleas (Parmenter et al., 1999; Xu et al., 2015). The combination of these environmental sensitivities, when playing out across the scale of ecosystems, can lead to widespread synchronicities in plague epizootic periods (Kausrud et al., 2007).

All of these lines of evidence suggest that plague should be broadly sensitive to environmental change, and that in systems where trends in plague occurrence have been tracked, an anthropogenic signal might be detectable. The United States is the perfect system to test this approach, as data in this region are particularly abundant; human case data goes back over a century, to plague's first introduction on the Pacific coast in early 20th Century (Adjemian et al., 2007; Ben Ari et al., 2008; Link, 1955). Moreover, the US Department of Agriculture (USDA) has collected plague seropositivity data from wildlife for multiple decades through the USDA National Wildlife Disease Program (Bevins et al., 2012). In total, these national datasets include more records than many global studies of pathogen distributions (Carlson et al., 2019), making this system a data-rich testing ground. In addition, these data also cover nearly a century of environmental change, a temporal scope that allows time-specific ecological niche modeling to be implemented. This also allows us to revisit one of the only previous attempts at this approach, which compared models of plague risk in the western United States based on case data in three multiyear time slices (1965-1969, 1980-1984, and 19951999), and concluded that plague risk had expanded since 1950 and would continue to do so in future (Nakazawa et al., 2007).

In this study, we revisit this prediction by using two independent data streams (human cases and wildlife serology) in a machine learning model called Bayesian additive regression trees (BART) (Carlson, 2020) (see Methods for a detailed explanation). Section 1 Climatic reconstructions are readily available for the duration of our study (1950-2017), allowing us to use annual climate layers (including long-term anomalies) corresponding to the year of each plague case. This pairing allows us to improve model precision relative to long-term averages, to differentiate areas of ephemeral versus persistent risk, and to identify the fingerprint of environmental change in risk trends. We also test whether the distribution of plague in this region is responsive to rodent biodiversity or soil chemistry and macronutrients, offering detailed insights into the factors that maintain plague risk. Finally, we propose a new approach that harnesses BART with random intercepts (riBART) to account for historical variability in detection and sampling, allowing us to confidently identify the signal of changing environmental conditions in plague occurrence over time. In doing so, we propose the first extension of ecological niche modeling that nods toward the ultimate aim of detection and attribution of anthropogenic climate change impacts on the geographic distribution of infectious diseases.

\section{2 | METHODS}

Despite recent interest in modeling the distribution of major infectious diseases (Hay et al., 2013; Kraemer et al., 2016), there is no definitive global map of plague reservoirs. All existing global plague maps have been derived from expert opinion (Stenseth et al., 2008); all modeled products so far have been produced for national or continental scales (see Table S2). Plague ecology is regionally variable enough that this patchwork approach has the advantage of being tailored to relevant local predictors. However, the mix of modeling methods, variables, and spatiotemporal scales makes it nearly impossible to compare these models and develop any consensus on the biological or geological factors that determine where plague reservoirs can exist, and where not. In this study, we adapt predictors that have previously worked in other similar work on plague, and develop novel models of spatiotemporal risk patterns in the western United States based on human and wildlife data spanning from 1950 to 2017.

\section{1 | Data}

Our study is designed around two independently collected datasets, with only a small amount of temporal overlap. Together, they provide as comprehensive a picture of plague in the United States as possible.

\subsection{1 | Human case data (1950-2005)}

Human cases of plague occur sporadically but consistently in the Western United States, driven partially by exposure to infected cats and dogs that have acquired the infection outside of the home. The vast majority of the human cases in the United States are infected with the bacterium through flea bites (Campbell et al., 2019), which typically leads to bubonic plague if the infection is deposited into the skin tissue and results in an infection of the lymphatic system, or (less commonly rarely) as septicemic plague if the infection is deposited in the blood stream (Bosio et al., 2020). In only about $3 \%$ of the human cases, the disease manifests as pneumonic plague, when the infection was acquired by inhaling infectious droplets coughed up by infected animals or humans (Campbell et al., 2019). 
Confirmed plague cases are mandatorily reported to the US Centers for Disease Control and Prevention (CDC) Emergency Operations Center. CDC surveillance data are actively maintained on plague, and has been previously published in summary form as county totals (Ben Ari et al., 2008). We reused these data, which have been anonymized by previous researchers, and had case geolocations aggregated to county totals. To georeference them, we randomly sample a number of locations within each county equivalent to annual case totals. A total of 860 plague cases are recorded over the interval, with an average of 7.7 cases per year, across 490 counties in the American west.

\subsection{2 | Wildlife serology data (2000-2017)}

Wild animals are routinely exposed to $Y$. pestis in endemic regions, including the United States. Infection leads to substantial morbidity and mortality in some species (e.g., prairie dogs), but other species (e.g., coyotes) readily survive infection, with antibodies to $Y$. pestis being the only indication of exposure. This is especially true for predators, which can be exposed through consumption of plague-positive rodents or through bites from plague-positive fleas. These predator species do not necessarily play a direct role in plague transmission and dynamics, but instead act as sentinels of plague activity on the landscape (Brown et al., 2011; Gage et al., 1994). Correspondingly, the USDA National Wildlife Disease Program tests wildlife for evidence of plague exposure throughout much of the western United States. Testing was conducted using a hemagglutination assay (Chu, 2000) at the CDC until 2011. A majority of samples collected after 2011 were tested using a bead-based flow cytometric assay with a lower limit of detection (Chandler et al., 2018). In total, the version of the dataset we used spanned February 13, 2000 to January 29, 2018, with a total of 41,010 records, including 5,043 animals that tested positive. Of those records, the vast majority are coyotes (32,825 animals including 4,812 that tested positive). Species from the order Carnivora make up $92 \%$ of the dataset, followed by Rodentia (6\%), and the remaining came from a variety of taxonomic groups (Artiodactyla, Lagomorpha, Didelphimorphia, Cingulata, and Eulipotyphla). The most commonly tested rodents were beavers (Castor canadensis; $n=1,609$ ), nutrias (Myocastor coypus; $n=204$ ), and muskrats (Ondatra zibethicus; $n=94$ ).

\subsection{3 | Environmental covariates}

The transmission ecology of plague shares features with both vector-borne systems (e.g., malaria or dengue fever) and soil-borne pathogens (e.g., anthrax or melioidosis). The predictors we have chosen here are informed by predictors that have performed well for other plague mapping projects (Table S2), and were all expected to be informative as drivers of host ecology, vector competence, and/ or soil persistence.

Most studies that map infectious diseases with machine learning methods (i.e., ecological niche models) use long-term climate averages, paired with occurrence data that sometimes span decades of unstable environmental conditions. In contrast, we used timespecific climate data paired with-and extracted for-the year of each data point in the occurrence data. This allowed us to make yearly spatial predictions of the distribution of plague risk, and consider the extent of transmission risk as a dynamic process rather than a static surface. We held nonclimate predictors constant, assuming them to either be invariant (elevation) or be long-term averages (soil and rodent richness); in a more advanced retrospective, it might be possible to reconstruct the impacts of land use change by adding yearly resolution to these covariates, but these data do not currently exist.

\subsection{4 | Climate}

We derived all climate data (1950-2017) from PRISM, a historical reconstruction of climate in the continental United States, derived from a mix of weather station data and climatologically aided interpolation (Di Luzio et al., 2008). From the PRISM dataset, we used cumulative annual precipitation and annual mean, minimum, and maximum temperatures. We also generated two "anomaly" variables, given on a pixel-by-pixel basis as the difference between the annual value and the long-term average, divided by the variance. These data were downloaded in 2.5 arcminute grids ( $4.5 \mathrm{~km}$ at the equator), which was used as the standard resolution for the rest of the project.

\subsection{5 | Soil}

We assembled a set of seven predictor layers for soil persistence of plague that were informed by both laboratory experiments on plague transmission and previous efforts mapping soil-borne pathogens like anthrax (Bacillus anthracis). We aimed to develop a cohesive set of predictors characterizing the $C$ layer ( $1 \mathrm{~m}$ depth); rodent burrows in the American west can go up to $2 \mathrm{~m}$ deep in the soil, but macronutrient data are limited at this depth. We used the most recent version of the ISRIC SoilGrids global dataset at $250 \mathrm{~m}$ resolution (Hengl et al., 2017), and selected gridded layers of soil pH, cation exchange capacity (base saturation), and the concentration of sand, clay, and organic content in the top 60-100 mm layer of soil. Sodium, calcium, and iron concentrations were derived from a national survey of soil geochemical properties, published in raw form as USGS data series 801 (Smith et al., 2011, 2013). We extracted all point samples of mineral concentration in the $\mathrm{C}$ horizon, given in weight percent, and then developed a rasterized layer for these macronutrients by kriging the point data, using the autoKrige function in the automap package (Hiemstra et al., 2013).

\subsection{6 | Additional covariates}

Rodent species richness was derived by stacking species IUCN expert range maps for the Rodentia, and rasterizing the richness layer using 
the fasterize package (Ross, 2020). IUCN maps are widely agreed to be unreliable at fine spatial scales for many species (Ramesh et al., 2017), but, in aggregate, are a suitable proxy for coarse gradients in richness. Elevation data were scraped using the elevatr package in $\mathrm{R}$ (Hollister et al., 2017), which pulls gridded elevation data from the AWS Open Data Terrain Tiles. We pulled elevation data at resolution "6," which returns elevation rasters in $2446 \mathrm{~m}^{2}$ grids at the equator ( 1.3 arcminutes), and aggregated to the native resolution of the other grids.

\section{2 | Modeling}

Dozens of statistical methods have been applied to species distribution modeling in the past few decades, with a wide range of performance (Norberg et al., 2019). Over the past few years, classification and regression tree (CART) methods-including random forests and boosted regression trees-have become especially popular for mapping the geographic distribution of infectious diseases (Bhatt et al., 2013; Carlson et al., 2019; Hieronimo et al., 2014; Pigott et al., 2014; Richards et al., 2020; Shearer et al., 2018). Here, we use a fairly new method, Bayesian additive regression trees (BARTs), implemented with the $\mathrm{R}$ package embarcadero as a species distribution modeling wrapper for the dbarts package (Carlson, 2020; Dorie, 2020). BART is a powerful new method with growing application in computer science, and often performs comparably to other CART methods like random forests and boosted regression trees (Chipman et al., 2010). In the embarcadero implementation, BARTs have several unique features that make them a powerful tool for disease mapping, such as model-free variable importance measures, and automated variable selection; posterior distributions on predictions, as a measure of uncertainty; posterior distributions on partial dependence plots; two-dimensional and spatially projected partial dependence plots; and various extensions, including random intercept models.

Like other CART methods, BART makes predictions by splitting predictor variables with a set of nested decision rules ("trees") that assign estimated values to terminal nodes ("leaves"). Predictions are generated based on a sum-of-trees model, where a set of $n$ trees with leaves $\left(T_{1}, M_{1}\right), \ldots,\left(T_{n}, M_{n}\right)$ each make predictions $g(\cdot)$ that are added together, for a total estimate:

$$
\widehat{Y}=f(X)=\sum_{j=1}^{m} g\left(X ; T_{j}, M_{j}\right)+\varepsilon ; \quad \varepsilon: \mathcal{N}\left(0, \sigma^{2}\right)
$$

For logistic classification problems (like species distribution modeling), BART uses a logit link function:

$$
\widehat{Y}=f(X)=\Phi\left[\sum_{j=1}^{m} g\left(X ; T_{j}, M_{j}\right)\right]
$$

where $\Phi$ is the standard normal cumulative distribution. An initial set of $n$ trees is fit, and then altered in an MCMC process based on a set of random changes to the sum-of-trees model (e.g., new splits added, levels rearranged, or leaves pruned). An initial burn-in period is discarded, and then a set of posterior draws $\left(f^{*}\right)$ create the posterior distribution for $p(f \mid y) \equiv p$ (trees $\mid$ data).

BART is easily implemented out-of-the-box, even with a full Bayesian MCMC component. Three priors control the ways decision trees change: the probability each variable is drawn for a split, the probability of splitting values tested, and the probability a tree stops at a certain depth. In the simplest form, the first two can be set as uniform distributions, while the latter is usually set as a negative power distribution; they can also be adjusted using a full cross-validation approach. This is handled automatically in the dbarts package, for which embarcadero is a wrapper. More advanced implementations with complex prior design are sometimes appropriate; for example, a Dirichlet distribution on the variable importance prior can help identify informative predictors in high dimensionality datasets (dozens or hundreds of covariates). However, in our case, we had confidence all variables were biologically plausible based on expert opinion.

\subsection{1 | The base models}

We ran two separate baseline models, the first using human data from 1950 to 2005, and the second using the wildlife data from 2000 to 2017. For the human model, we used the number of cases recorded each year in each county to generate a set of random georeferenced pseudopresence points. We then generated seven pseudoabsence points in each year to create a roughly balanced design, for a total of $n=430$ pseudopresence points and $n=392$ pseudoabsence points. For the wildlife model, we balanced the design by subsampling seronegative animals in equal number to seropositive ones, for a final $n=5,002$ true presence points and $n=4,759$ true absence points.

Both models were run with the full predictor set, followed by an automated variable set reduction procedure implemented in embarcadero that formalizes the recommendations of Chipman et al. (2010). In BART, variable importance is "model free," measured as the number of splitting rules involving a given variable (but incorporating no information on the proportional effect on the outcome variable, or proportional improvement in the model predictions). In models with fewer trees (small $n$ ), informative variables tend to be selected more often, while uninformative variables are selected rarely or drop out entirely. This property of BART establishes a rubric that can be used to identify an informative variable set. First, an initial model is fit with all variables 100 times each for six different settings of ensemble size ( $n=10,20,50,100,150$, and 200 trees). Plotting the average importance of variables at each level offers a qualitative diagnostic of how informative each predictor is. Next, an initial set of 200 models with $n=10$ trees are run, and variable importance is recorded and averaged across models. Models are run again (200 times) without the least informative variable from the first fit, and this is performed iteratively until only three variables remain; the variable set with the lowest average model root mean square error (RMSE), and therefore highest accuracy on the training 
data, is selected. Finally, we plot variable importance (including standard deviations based on model permutations).

Final models were run with the reduced variable set, with recommended BART model settings (200 trees, 1000 posterior draws with a burn-in of 100 draws) and hyperparameters (power $=2.0$, base $=0.95$ for the tree regularization prior, which limits tree depth). We then used the retune function in embarcadero to run a full crossvalidation panel on the three prior parameters. retune runs a full cross-validation across the $\mathrm{k}$ hyperprior (values of 1,2 , and 3 ), the base parameter ( 0.75 to 0.95 in increments of 0.05 ), and the exponent parameter ( 1.5 to 2 in increments of 0.1 ), and returns the model with the parameter combination that generates the minimum root mean squared error.

For the wildlife model, the final variable set included: temperature mean, maximum, and anomaly; rodent richness; elevation; and five soil traits (calcium, sodium, iron, clay, and sand). The model validated well on training data (AUC $=0.836$ ). For the human model, the final variable set included a similar subset: precipitation anomaly; temperature mean, maximum, and anomaly; rodent richness; elevation; and four soil traits (sodium, iron, clay, and calcium). The model also validated well on training data $(A U C=0.909$ ).

\subsection{2 | Alternate formulations}

As a final check of model performance, we ran a separate model with the same predictor sets that withheld the years 2000-2005 from both. On the test dataset for humans $(n=64)$, the model performed very well by the standards of external cross-validation (AUC $=0.820)$; on the test data for wildlife $(n=796)$, the model also performed well (AUC $=0.775)$. This indicated that both models were performing adequately.

We also recognize that model design can have a substantial effect on machine learning performance, and the downstream biological inference made by using ecological niche models. Given that BART is a relatively new method, it has been comparatively underexplored in this regard, and so a standard panel of "best practices" has not yet been recommended in the literature. However, for transparency about model uncertainty and the influence of subjective decisions on model outputs, we produced four major alternate formulations. First, we produced models that included all variables, rather than using the variable set reduction procedure, for both the human data (Figures S20-S22) and wildlife data (Figures S23-S25). We additionally considered two alternate formulations of the wildlife model. In the first, we used pseudoabsences instead of the true absences available in the data (Figure S26). Though this increased model AUC (0.929), and allowed slightly different balancing of the data, it lead to visually apparent overfitting. Finally, we ran an alternate model only using the coyote data in the NWDP dataset, which also performed adequately ( $\mathrm{AUC}=0.826$; Figure S27). Both models were ultimately not selected because they left available, biologically meaningful data unused, and both produced predictions that were slightly less congruous with the human model.

\subsection{3 | Prediction, delineating foci, and measuring change}

Although the models were trained over different intervals, the continuous and standardized set of predictors allowed cross-prediction over the entire extent of the study (1950-2017). For each layer of annual prediction, we thresholded suitability based on a modelspecific threshold chosen to maximize the true skill statistic on the test data. We mapped areas of "unstable foci" as any region with at least 1 year of suitability, and "stable foci" as any region suitable in every year over the 70-year interval. This allowed us to compare long-term spatial patterns between the two models.

\subsection{4 | Random effects models for interannual variation}

Prevalence changes year-to-year in both the data and modeled landscapes, but detecting the signal of climate change in that fluctuation can be challenging. There are several reasons prevalence could vary across years: (1) incidence is stochastic but temporally autocorrelated; (2) normal climatic variability (e.g., the Pacific Decadal Oscillation) or other socioecological trends (e.g., rising human populations) might also contribute to interannual variation, including nonlinear trends over time; (3) anthropogenic climate change is directly driving changes in plague risk, or indirectly changing the ecology of the involved species; (4) sampling effort varies between years (for wildlife); or (5) detection rates could change between years, due to testing or surveillance. The last of these is particularly relevant as a possible confounder, given that wildlife diagnostics changed in 2011. A positive trend in plague risk might be generated by increased climatic suitability for plague tranmission, but could also be generated by a consistent increase in plague detection due to improved diagnostics and increased sampling effort, loosely collinear with warming temperatures on the scale of 20 to 70 years.

We propose a new method that uses machine learning approaches (i.e., ecological niche models) to detect the signal of environmental change while adjusting for confounders at a high level. The approach is loosely modeled off the ideas underlying econometric approaches to climate change detection and attribution, which usually use fixed effects panel regression to control for spatiotemporal confounders in climatic signal. By attributing as much variance as possible to spatial, temporal, and other confounders, and then identifying climatic signal in the remaining variance, these approaches can pinpoint the signal of environmental change with a high degree of confidence. So far, no analog to these approaches exists for ecological niche models. Only a handful of studies have even added temporal heterogeneity to ENMs; so far, we know of none that have also independently controlled for interannual variation in detection, sampling effort, or species prevalence.

A solution to temporal confounders is particularly needed in this study, given the challenges of the time-specific approach. In default settings, BART predictions converge on observed 
prevalence, that is, $\hat{Y}=E[Y]=P(Y=1)$. For this reason, we balance the presences and absences, so that the model is as close to $\hat{Y} \sim \mathcal{N}\left(0.5, \sigma^{2}\right)$ as possible. This produces a unique challenge for time-dependent modeling. Presences are distributed unevenly across years, and consequently, so is positivity. In the human model, this arises artificially, because pseudoabsences are generated evenly across years. We chose this approach to avoid overrepresenting years with more cases in the data, which would introduce an additional collinearity, but as a result relative prevalence varies substantially. This bias also affects the wildlife model more organically; although the number of points per year varies independently of test positivity (cor $=0.113, p=0.687$ ), because most sampling is passive, there is still a wide range in annual prevalence (28\% in 2006 versus $80 \%$ in 2017 , both years with several hundred records), with a net trend toward higher positivity over time. Because prevalence varies between years in both models, the resulting with environmental change could confound the detection of meaningful signals.

Inspired by the econometric approach, we propose a use case for the random intercept BART model (riBART), which has recently been proposed as an extension of the method for clustered outcomes. The approach adds a random intercept term to the model (separate from the tree-fitting process) based on the identified $K$ clusters

$$
\widehat{Y}=f(X)=\Phi\left[\sum_{j=1}^{m} g\left(X_{k} ; T_{j}, M_{j}\right)\right]+\alpha_{k}
$$

where the random intercepts $\alpha_{k}(k \in 1: K)$ are normally distributed around zero (i.e., the $K$ groups are assumed to have normally distributed, independent additive effects on the outcome variable). The error structure of the random effects and the sum-of-trees model are assumed independent. Here, we propose that the model can be fit as usual with a random intercept for year, as a way of accounting for temporal heterogeneity as a possible confounder. The yearly random in tercept absorbs most of the interannual variation in plague prevalence (i.e., the relative ratio of presences and absences in the data), such that residual variation in prevalence should be roughly constant across years. Identifying the climatic signal in these residual data, and then examining predicted prevalence (without random intercepts) based only on environmental change, allows more confident statements about how environmental change contributes to shifting disease risk.

We revisited the two main models, and used riBART to add an annual random intercept to our model for each year, which we refer to throughout as the "detection" models. Fitting climateplague response curves after this detrending decouples the possible collinearity between climate trends and coarse interannual signal in the data, which may be driven by natural variation in prevalence or other confounders (e.g., the 2011 change in wildlife testing protocols). We fit both detection models with a random intercept for year, plotted the random effects, and predicted over the 70-year interval without the random effect included. (All functionality to implement SDMs with riBART is available in embarcadero as an updated release.)

\subsection{5 | Detecting change over time}

To estimate trends for change over time, we fit a linear slope through each pixel-by-year. Multiplying by 68 years, we were able to estimate total percent change in suitability since 1950 in a given pixel. We did not limit these to pixels with a significant trend, as any frequentist significance test iterated over millions of pixels would be mostly meaningless. We generated these maps for the two primary models and the two detection models (Figure 3), as well as (in the supplement) for mean temperature and precipitation (Figures S18 and S19).

\section{3 | RESULTS}

\section{1 | The distribution of plague}

We generated two primary models of plague over time. The first covered 9,761 animals sampled for plague (2000-2017), and performed well (training AUC $=0.836$; Figure $\mathrm{S} 1$ ). The second covered a total of 430 human cases of plague (1950-2005), and performed very well (training $\mathrm{AUC}=0.909$; Figure $\mathrm{S} 2$ ). When both models were rerun with an overlapping "test period" of 2000 to 2005 withheld, they performed adequately, with the human model ( $A U C=0.820$ ) performing better than the wildlife model ( $A \cup C=0.775$ ). As both models performed well in temporal cross-validation, we used both to make annual predictions from 1950 to 2017, and split predictions into binary presence or absence risk maps for each year using the true skill statistic.

Both models found that the majority of plague risk in the western United States is, as expected, found west of the 100th meridian (Figure 1). The human model mostly predicts risk in the "Four Corners" region (Utah, Colorado, Arizona, and New Mexico), where that risk is relatively stable across years. In contrast, the wildlife model predicts risk fairly expansively west of $100^{\circ}$, including at much higher latitudes than the human risk model. Risk varies much more across years in this model, but several areas are predicted to be environmentally suitable across years from Montana to west Texas. The suitable areas identified by the wildlife model in the southwest are less uniform than the human model, likely reflecting a finer scale differentiation of risk. There are two main reasons the human model might discriminate less in this region: human cases may be reported in different locations than the site of initial spillover, and occurrence points were randomly resampled at the county level (as data have been previously de-identified).

For the most part, we found that risk areas identified in the human model were a subset of the much broader predictions made by the wildlife model (Figure 2), with three major exceptions. The human model identified much broader risk in southern Arizona and New Mexico, likely due to how the cases were randomized at county levels. The human model also predicted areas of risk further east, in regions like east Texas or Oklahoma where plague is not known to be endemic (and, in this regard, the wildlife model better captures the 

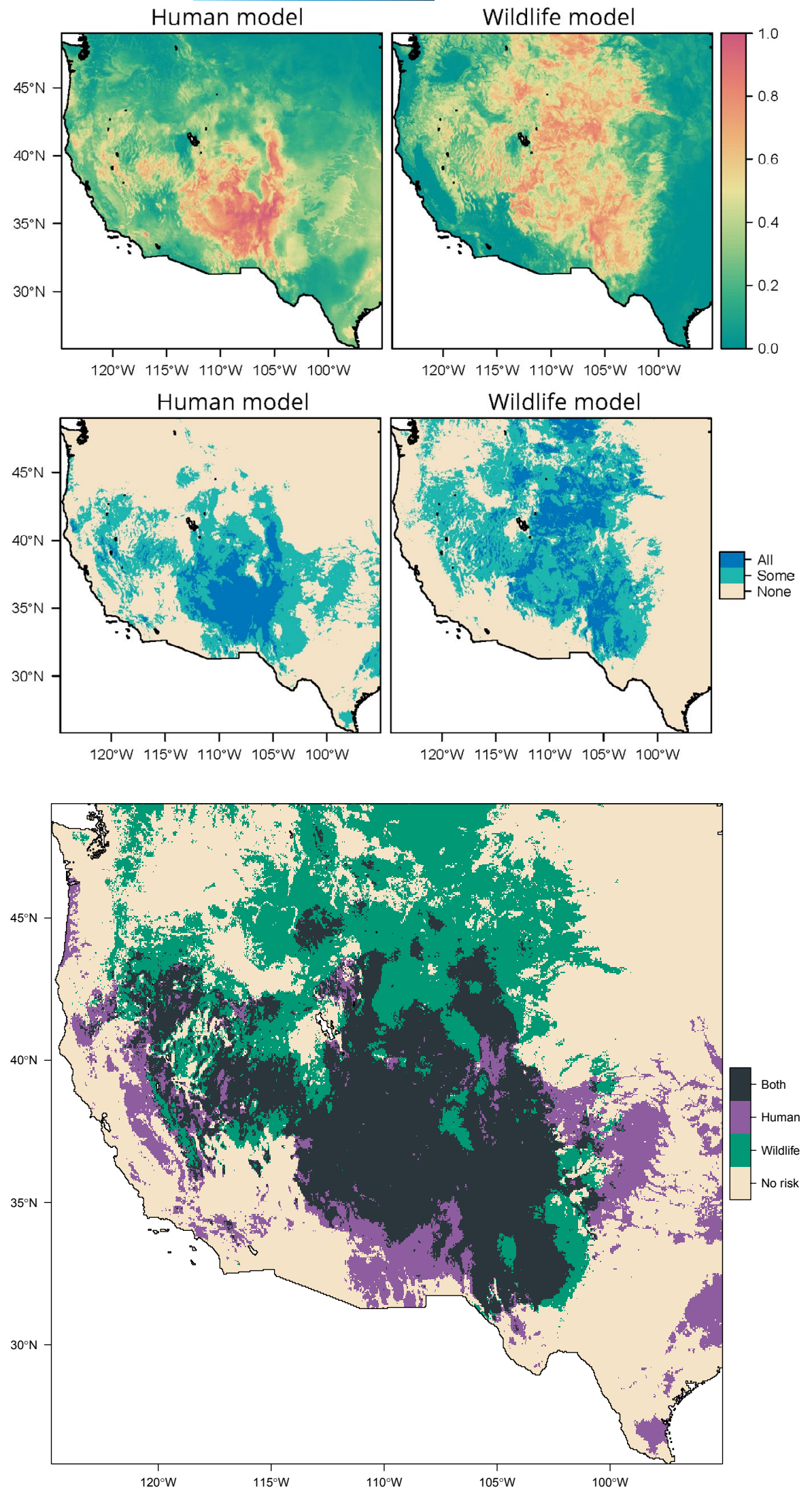

FIGURE 1 Suitability for plague across all years (1950-2017), for humans (left) and wildlife (right). Top panels give mean suitability across all years; bottom panels show areas identified as suitable in no years, at least one, or all 68 years
FIGURE 2 The wildlife model's predictions largely encompass the human model's predictions, except in southern Arizona and California (where predictions extend into other areas of suspected plague risk) and west Texas (too far east for plague reservoirs) known distribution), but conditions may be broadly favorable. Finally, and most notably, the human model predicted plague risk throughout California, in places that have previously been identified as high risk (Holt et al., 2009). This likely reflects a deficit of data from Californian sources in our wildlife model, as state wildlife surveillance is curated independently. Together, our findings indicate the value of comprehensive surveillance, and the possibility that zoonotic reservoirs may be more expansive than areas of known spillover. 
FIGURE 3 Total percent change in plague suitability, 1950 to present, in the human (top) and wildlife models (bottom), before (left) and after (right) adding random intercepts to control for interannual variation

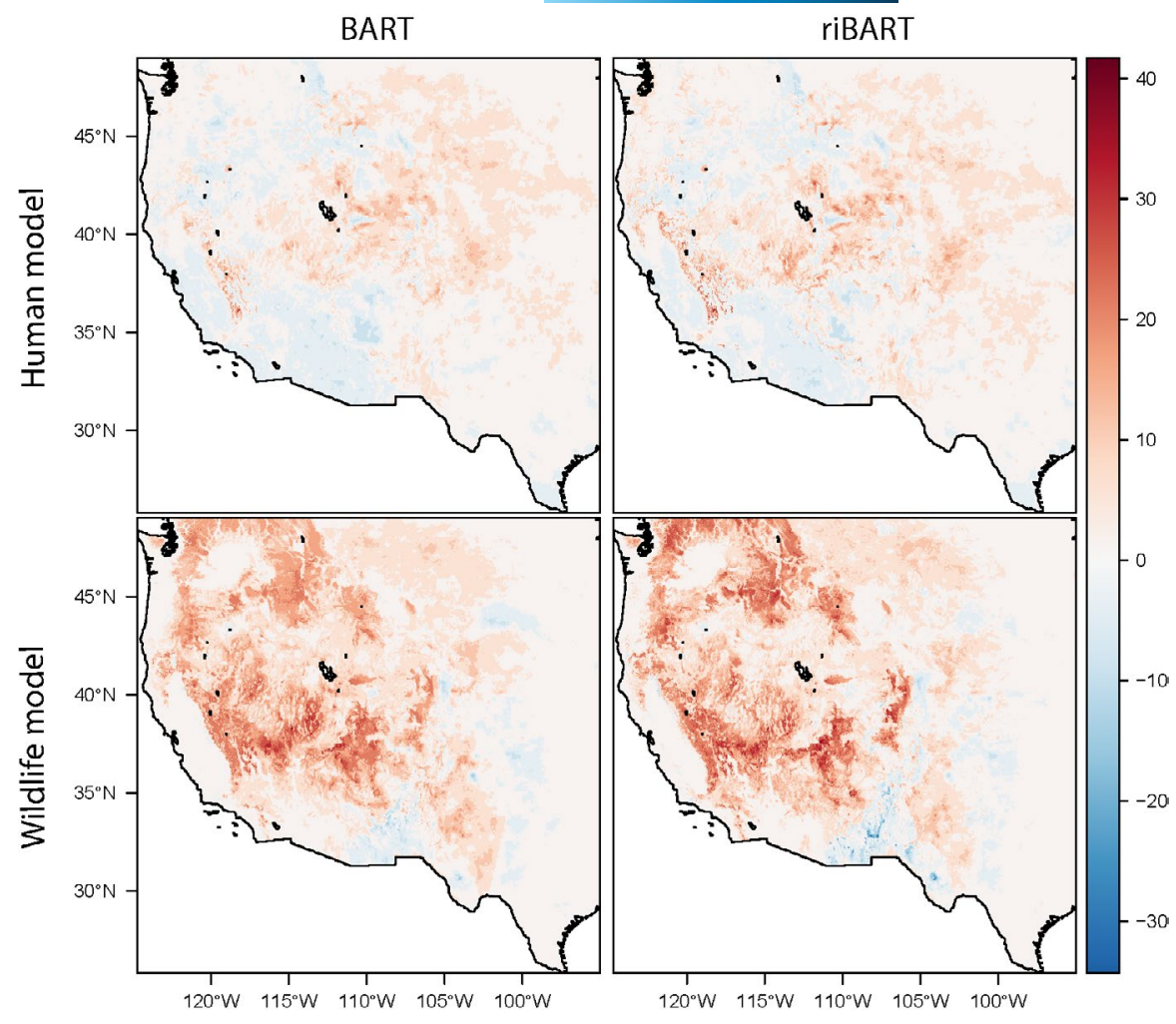

\section{2 | Ecological insights}

Our models identified a number of intersecting factors that maintain plague reservoirs and create the right conditions for spillover, many of which have been previously identified by ecological and epidemiological models (Figures S3-S9). A handful of factors are important in both animal and human spillover models, and have similar response profiles: elevation, with higher risk at higher elevations; rodent species richness, with a similar positive effect; and the sodium $(\mathrm{Na})$ and calcium ( $\mathrm{Ca}$ ) content of the soil, both with a negative effect on plague risk. As these factors are shared between the models, we can tentatively conclude that these factors relate to what happens in the wildlife, and are not substantially altered by the additional spillover process that the human model incorporates. A fourth environmental factor that is significant in both models is temperature, but with different response profiles in how means, maxima, and anomalies in temperature affected the risk of plague. Finally, we found strong effects of clay and iron content of the soil, which are shared between the two models but follow different profiles, as well as the sandiness of the soil (wildlife model only) and the variability in annual precipitation within the area (human model only). A list of all variables and abbreviations is given in Table S1.

\subsection{1 | Elevation}

Both models indicate that plague risk increases at higher elevations, particularly above $2,000 \mathrm{~m}$, compatible with previous findings in this system (Brown et al., 2010; Eisen et al., 2007; Holt et al., 2009;
Walsh \& Haseeb, 2015). Using spatial partial dependence plots, we were able to show that the abrupt transition in plague suitability at the 100th meridian $\left(100^{\circ} \mathrm{W}\right)$ was driven by the elevational layer in both models, and not suitably explained by any bioclimatic factors (Figures S10 and S11). Elevation has also been previously associated with plague on other continents (Abedi et al., 2018; Eisen et al., 2012; Moore et al., 2015; Neerinckx et al., 2008, 2010b; Qian et al., 2014), and while the general trend is that there is a lower threshold elevation (and an upper limit, at the extreme altitudes in the Himalayas), that threshold differs substantially between countries. For example, Brazil's plague reservoirs start at $500 \mathrm{~m}$ above sea level, and are limited by the landscape to no more than 1000 m (Giles et al., 2011), while Madagascar's urban plague reservoir in Mahajanga is at sea level (Giorgi et al., 2016), as are the plague reservoirs surrounding the Caspian Sea in Central Asia (Kutyrev \& Popova, 2016). Elevation therefore seems to represent the local ecology and distributional limits of fleas and rodents, rather than a global proxy for a bioclimatic or atmospheric variable (e.g., partial $\mathrm{CO}_{2}$ pressure).

\subsection{2 | Rodent richness}

Likewise, both models found a higher suitability for plague in areas with higher rodent richness, with the factor being only second to elevation in importance in the human plague-risk model. This points to the possibility that high-elevation hotspots of rodent biodiversity may help maintain enzootic plague transmission, a possible case of the biodiversity amplification effect that has also been found by similar work in China (Sun et al., 2019). As in China, it is unclear whether 
the increased biodiversity itself has a positive effect on plague maintenance, or whether it merely signals an increased chance that certain key rodent species (particularly synanthropic ones) are locally present. If there are positive, general associations between rodent diversity and plague risk, this would be an exception to widespread evidence of biodiversity dilution effects for other vector-borne diseases (Rohr et al., 2020). Most theoretical models of the dilution effect rely on a skewed distribution of host competence, where higher host diversity leads to reduced transmission in the narrow subset of competent hosts (Johnson et al., 2013; Miller \& Huppert, 2013; Schmidt \& Ostfeld, 2001); plague is perhaps uniquely capable of infecting and causing disease in hundreds of host species (Mahmoudi et al., 2020), and therefore may not exhibit these dynamics, though only a limited number of species develop a high enough bacteremia to infect a feeding flea. Alternately, it may be that scale underlies this pattern; theory suggests that dilution effects are strongest at small scales, while amplification effects may be normal at continental scales (Buck \& Perkins, 2018; Halliday \& Rohr, 2019). Finally, it might simply be that plague behaves differently than other vector-borne diseases because plague can also spread through pneumonic transmission and prey consumption, which produce different dynamics.

\subsection{3 | Climate}

Temperature was a universally important predictor across all models, while surprisingly, precipitation only minimally influenced predictions. In the wildlife model, we found a loose peak around $7^{\circ} \mathrm{C}$ but overall a negative relationship between mean temperature and plague risk-an unusual response curve for a vector-borne disease (Mordecai et al., 2019). In the human model, risk is highest around a mean temperature of $11^{\circ} \mathrm{C}$, and suitability increases steeply above a maximum temperature of $10^{\circ} \mathrm{C}$ but stabilizing around $25^{\circ} \mathrm{C}$. Despite some unusual features, these results are broadly consistent with prior experimental work on the mostly wildlife-associated Oropsylla montana and the more synanthropic Xenopsylla cheopis, two of the main plague vectors in North America (Eisen et al., 2009). Lemon et al. (2020) report that a significantly larger fraction of O. montana become infected with plague when feeding on an infected blood source at $10^{\circ} \mathrm{C}$ than at $21^{\circ} \mathrm{C}$; Williams et al. (2013) similarly report a peak transmission rate for $\mathrm{O}$. montana at $10^{\circ} \mathrm{C}$ across a temperature range from 6 to $23^{\circ} \mathrm{C}$. In contrast, the survival rate of infected $X$. cheopis is markedly higher at $21^{\circ} \mathrm{C}$ compared to $10^{\circ} \mathrm{C}$ (Lemon et al., 2020; Schotthoefer et al., 2011), and the highest plague transmission efficiency is observed at $23^{\circ} \mathrm{C}$ (Schotthoefer et al., 2011), better matching the temperature response in the human model. In addition to vector competence, many other factors of plague risk are temperature sensitive, from the straightforward (e.g., flea infestation levels (Poje et al., 2020)) to the more abstract (e.g., some colder temperature ranges may characterize the rural areas in the Rocky Mountains where people live alongside plague reservoirs). Disentangling these factors may shed further light on the more unusual aspects of the thermal response curves we identified.
In addition to the effect of long-term climatic averages, the temporal structure of the model allowed us to detect a strong effect of interannual variability. In the wildlife model, we observed an increase in plague prevalence during anomalously warm years, a result that has been previously reported for semi-arid desert ecosystems (Stenseth et al., 2006), as well as for human cases in the United States (Ben Ari et al., 2008). Warmer years are likely to increase rodent density, both directly through mild winters (Frigessi et al., 2005) and indirectly through higher primary productivity; flea populations in turn tend to follow rodent density, with some degree of lag (Frigessi et al., 2005; Reijniers et al., 2014; Samia et al., 2011). In contrast, in the human model, spillover was most likely in anomalously wet, cold years. This matches previous findings in other systems (Reijniers et al., 2014; Samia et al., 2011; Schmid et al., 2015), which have been attributed to another kind of tropic cascade: when seasonal fluctuations become unfavorable to rodent populations after a recent high, and these rodent populations contract, fleas aggregate on the remaining rodents, both facilitating the dissemination of plague between rodents, and making fleas more eager to seek secondary hosts to feed on, thus leading to increased spillover risk.

\subsection{4 | Soil}

Finally, we found that both models provided evidence that the longterm persistence of plague foci is related to properties of the soil. Our modeling suggests that in vivo, soils with higher proportions of sand and intermediate proportions of clay ( 20\%-30\%) (Figure S8), low sodium and calcium contents, and mid-to-low concentrations of iron seem to be most conducive to plague. Although not included in either model after variable set reduction, we also found that soil $\mathrm{pH}$ may limit persistence, with more alkaline soils favored in the wildlife model. The observed response curves are somewhat unusual, given that both human and wildlife cases peaked in the raw data around a soil pH of 8.2-8.4 (Figure S12); it may be that this reflects collinearity with other soil traits, or simply a smaller effect of $\mathrm{pH}$ compared to other soil characteristics.

The role of a soil compartment in the maintenance of plague reservoirs has been under consideration for more than a century, and various aspects of a soil cycle of plague have been independently confirmed in laboratory settings. These include survival in the soil for months to years in a laboratory setting, either in association with amoebas (Acanthamoeba castellanii and Dictyostelium discoideum) or independently (Ayyadurai et al., 2008; Benavides-Montaño \& Vadyvaloo, 2017; Eisen et al., 2008; Markman et al., 2018); the existence of Y. pestis in soil in wildlife plague foci (Malek et al., 2017); the sporadic return from soil into a rodent population (Boegler et al., 2012); and geographic correlations between plague foci and various soil properties (Malek et al., 2017; Neerinckx et al., 2008, 2010b). Mechanisms through which these factors affect plague foci may be directly related to the bacterium, or through soil factors that influence the vector or the host. Fleas living in burrows, for example, are negatively affected in all aspects of their lifecycle (fecundity, 
development, survival, and activity) in environments with a 100 -fold higher level of $\mathrm{CO}_{2}$ (as a fraction of total molecules in the air) than the atmospheric fraction (Downs et al., 2015). This link to ventilation can explain the role of soil characteristics: a poorly ventilated burrow (impermeable, nonsandy soil) may reach up to 65-fold higher level of fractional $\mathrm{CO}_{2}$, whereas a unventilated permeable (sandy) soil would only reach up to 25 -fold higher levels, and a well-ventilated permeable soil would only reach up to sevenfold higher (Brickner-Braun et al., 2014). Likewise, soil mineral content could have downstream effects on the homeostasis of virulence-related minerals in the body of the host. As a parallel, one study in Brazil found that cattle grazing on iron-rich soil would lead to highly lethal infections of normally nonpathogenic Yersinia pseudotuberculosis, presumably by perturbing the ability of the host to bind iron away from being utilized by the bacterium during an infection (Warth et al., 2012). Both iron (Ell, 1985; Hooker-Romero et al., 2019; Quenee et al., 2012) and calcium (Fowler et al., 2009; Schneewind, 2016) are virulence factors of Y. pestis, and we tentatively hypothesize that plague foci persist better in regions where $Y$. pestis is not facilitated by the environment to be highly virulent.

\subsection{Detecting environmental impacts on change over time}

We found a strong temporal trend in both climate and plague risk since 1950 (Figure 3). To test whether this signal might be confounded by exogenous factors, we used a novel approach where we trained riBART for each year, and projected the model again without random effects over the 68-year period (see Methods). The random intercepts identified interannual variation in prevalence (Figures S13 and S14), detrended the data, and allowed the models to identify climate signal minus the confounder without substantially changing overall predictions (Figure S15). Subsequently, we predicted how suitability changed using the same model without random intercepts; this allowed us to be confident that the changing suitability we identified in these "detection models" was the consequence of constant relationships between temperature, precipitation, and plague transmission.

Both detection models identified a meaningful signal of temporal variation. The random intercepts identified a signal of rising prevalence through the wildlife dataset, particularly increasing after 2011 when the diagnostics were changed (Figures S13 and S14). In the human model, we identified a much more subtle long-term quadratic trend peaking in the 1980 s, matching a pattern that has been previously attributed to climate cycles like the Pacific Decadal Oscillation (Ben Ari et al., 2008). Surprisingly, the "detection" models identified an even stronger pattern of change over time (Figure S16). In the wildlife model, suitability increased an average of $4.8 \%$, and $4.9 \%$ in the detection model, with a much fatter tail to the distribution as well. In the human model, suitability increased an average of $1.7 \%$ from 1950 to 2017 , and $2.1 \%$ in the detection model. In much of the region, we found that plague suitability increased by 30 to $40 \%$ over

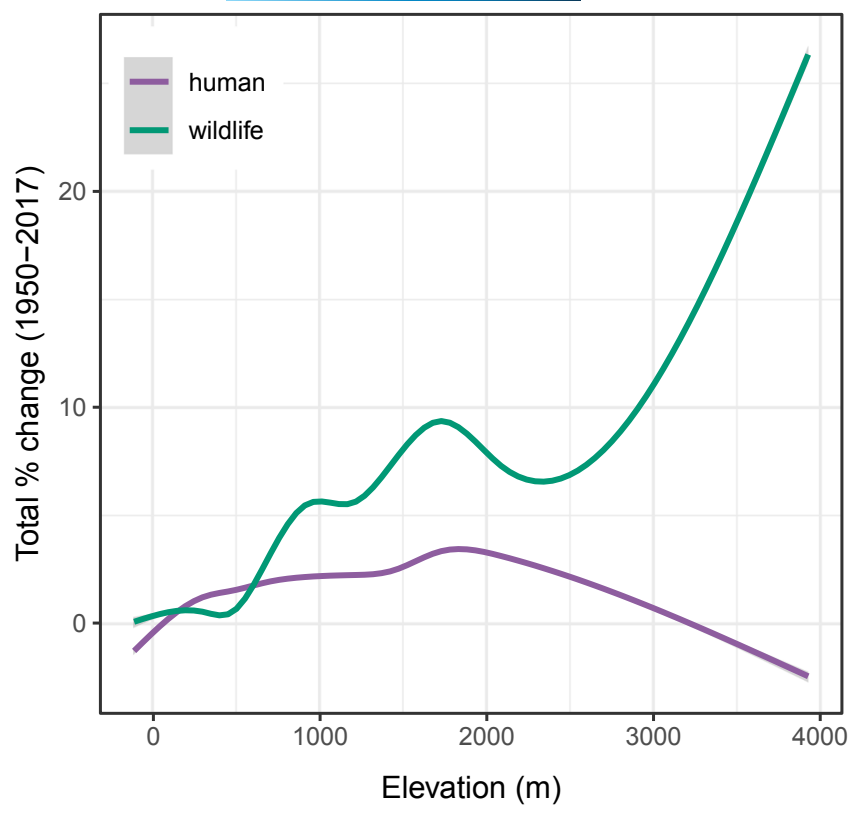

FIGURE 4 Environmental suitability for plague has increased substantially at high elevations for wildlife; risk of spillover has increased mildly at mid-elevations. Lines are given as generalized additive model smooth fits based on the detection models

the entire interval. We found that suitability rose most substantially in the wildlife model at high elevations, while spillover risk increased more gently, and peaked at mid-elevations (Figure 4, Figure S17). Because the detection models only predict change across years based on the temperature and precipitation variables, we are confident that the increase in plague suitability is driven by the long-term signal of warming (roughly $0.8^{\circ}$ in the region since 1950) and higher anomalous precipitation is responsible for these predicted changes (Figures S18 and S19). We conclude that, even with several confounding factors, environmental change since the 1950s may have helped plague reservoirs become established at higher elevations, and slightly increased the risk of spillover into human populations at mid-elevations. Over the coming half-century, previous work suggests that the shift toward higher elevations is likely to continue in this region (Holt et al., 2009).

\section{4 | DISCUSSION}

Our study shows that human and wildlife data can be used in conjunction to map plague reservoirs and spillover risk in the United States, and to make meaningful inferences about ecological drivers of transmission. We found support for two major hypotheses: the biodiversity amplification effect (higher rodent diversity supports establishment of plague foci) and the trophic cascade hypothesis (anomalously warm and anomalously wet, cold years can increase plague prevalence and spillover risk, respectively, through ripple effects of ecosystem productivity on rodents and flea populations). Support for these patterns has increasingly been found across 
systems, and points to a view of plague risk where weather conditions (and their impact on flea vectors) in rodent biodiversity hotspots are the primary driver of transmission and spillover. Though the plague "niche" may largely transcend any individual host species (Maher et al., 2010), in future, our understanding of these mechanisms might be further refined by exploring more granular variation among the species involved. Identifying "true reservoirs" is a nontrivial task in disease ecology (Becker et al., 2020; Viana et al., 2014); Yersinia pestis can infect hundreds of rodent species (Mahmoudi et al., 2020), and some species once considered key to maintain endemic plague are now known to be spillover hosts from unknown reservoirs (Colman et al., 2021; Danforth et al., 2018). Rodent habitat use adds another dimension to the problem: synanthropic and "wild" reservoirs may have very different richness hotspots (Sun et al., 2019), which may explain some differences between the geography of maintenance and spillover (as, alternately, could the geography of domestic cat and dog ownership (Campbell et al., 2019)). These patterns are further complicated by potential variation among fleas, with over two dozen experimentally verified vectors in the United States alone (Eisen et al., 2009), which vary in geographic distribution, thermal sensitivity, and affinity for wildlife and human hosts. All of these nuances may point to promising directions for future data synthesis and modeling.

We further found strong evidence that the North American distribution of plague is heavily influenced by soil conditions. The global distributions of soil-persistent bacteria like anthrax (Bacillus anthracis), tularemia (Francisella tularensis), and botulism (Clostridium botulinum) are known to be constrained by the biochemical properties of soil. Less is known about plague, which is not spore forming, and until recently was mostly thought to behave like a typical vectorborne zoonosis. It may be that soil properties affect the suitability of burrows for higher flea densities, or determine host homeostasis for minerals that impact the virulence of the infection; plague foci might therefore fall in the narrow range of conditions that can harbor higher densities of fleas, but do not substantially increase the lethality of the infection. However, increasing evidence also suggests that the bacterium can persist in the soil, possibly through symbiotic relationships with amoebas, for weeks to months-and possibly even years (Baltazard et al., 1964; Karimi, 1963). These complexities underscore the importance of a One Health approach while studying the ecology of plague, which-like anthrax and many other bacterial pathogens-circulates easily among fleas, rodents, other wildlife, humans, and the environment as one interconnected system (Carlson et al., 2018).

Developing a better understanding of plague in well-studied systems like the American West will help develop a broader picture of its ecology. At present, all global maps of plague foci have been compiled from expert knowledge; modeled products in the English language are limited to the western United States, China, and Africa (Table S2). In part, this reflects the challenges of sharing, aggregating, and consolidating surveillance data. It may also reflect concerns about model transferability, given that the complex multispecies dynamics of plague reservoirs differ greatly across ecosystems and continents. However, other pathogens with regional host communities and complex environmental persistence have been globally mapped through multinational coordination (Carlson et al., 2019), and the same synthesis is possible for plague. In the more immediate term, our model also strongly suggests that wildlife reservoirs extend to the US borders with both Mexico and Canada, and could plausibly extend beyond them (recently confirmed for the northern border (Liccioli et al., 2020), but the official World Health Organization map of plague (last updated 2016) includes no reservoirs in Mexico or Canada. Collaborating with national surveillance infrastructure in both countries may help resolve the boundaries of plague transmission more clearly, and reveal foci currently overlooked by global monitoring efforts.

Beyond plague, our study highlights the opportunity for medical geographers to develop new methods that are suited to a rapidly changing world. Here, we proposed two methodological advances that build on existing best practices in infectious disease mapping. First, time-specific covariates allowed us to train machine learning models on nearly a century's worth of data, improving precision compared to coarsely averaged predictors, and capturing the effects of environmental change. If this approach is integrated with others at finer temporal scales, such as those that consider seasonal aspects of transmission or spillover risk (Kaul et al., 2018; Schmidt et al., 2017), this could begin to set the foundation for an early warning system. Second, the use of random intercepts to remove data and detection biases, such as the serology method change in our data sample in 2011, is an important step toward testing climate change impacts using continuous-time data (similar to how econometric approaches resolve these problems in similar spatiotemporal analyses [Carleton \& Hsiang, 2016]). We propose that when this approach can be taken, it may be used as a first principles method for detecting the signal of environmental change in species' habitats. This could be a particularly important step toward synthesizing the impacts of climate change on the shifting presence and absence of disease data, especially in cases where prevalence and incidence data are lacking and panel regression approaches cannot be applied. However, this work will still need to be followed by proper "attribution" work that compares predicted patterns to counterfactual scenarios without climate change; at present, all we can conclude with certainty is that weather conditions have changed in a way that trends favorably for plague risk.

Our study also points to a number of gaps in our understanding of environmental change (and consequently, potential methodological limitations). The PRISM data offer a fairly comprehensive view of the recent climate in the United States, and allowed us to identify the role of temperature and precipitation in plague transmission. However, we held both soil and rodent predictor variables constant, and neither are stationary in reality. Soil has changed over the last century due to a combination of climate change and land use change, and unfortunately time-specific covariates are unavailable; in many cases, our soil layers had to be generated custom to this study, and for the rest of the world these data are even more sparse. Similarly, evidence is strong that most terrestrial species have responded to recent climate change by undergoing 
range shifts, especially along elevational gradients. If rodents have undergone range shifts, they may have encountered novel vector communities, and the relationship between richness and transmission could change. Similarly, if elevation acts in our models as a proxy for specific rodent-flea assemblages, range shifts could decouple the observed relationships between elevation and transmission. As other studies have pointed out, these challenges highlight the need to begin integrating zoonotic surveillance and biodiversity monitoring (Carlson et al., 2020).

\section{ACKNOWLEDGMENTS}

This work is supported by the Research Council of Norway (FRIMEDBIO project 288551).

\section{CONFLICT OF INTEREST}

The authors declare no conflicts of interest.

\section{AUTHOR CONTRIBUTIONS}

CJC performed the analyses. All authors contributed to the data, and to the conceptualization and writing of the manuscript.

\section{DATA AVAILABILITY STATEMENT}

Human case data in this study are taken from previous studies and are available online for researchers to reproduce our study. Wildlife data are available on formal request and approval from the US Department of Agriculture. All code are available at github.com/ cjcarlson/plague-wna.

\section{ORCID}

Colin J. Carlson (D) https://orcid.org/0000-0001-6960-8434

\section{REFERENCES}

Abedi, A. A., Shako, J.-C., Gaudart, J., Sudre, B., Ilunga, B. K., Shamamba, S. K. B., Diatta, G., Davoust, B., Tamfum, J.-J., Piarroux, R., \& Piarroux, M. (2018). Ecologic features of plague outbreak areas, Democratic Republic of the Congo, 2004-2014. Emerging Infectious Diseases, 24, 210. https://doi.org/10.3201/eid2402.160122

Adjemian, J. Z., Foley, P., Gage, K. L., \& Foley, J. E. (2007). Initiation and spread of traveling waves of plague, Yersinia pestis, in the western United States. The American Journal of Tropical Medicine and Hygiene, 76, 365-375. https://doi.org/10.4269/ajtmh.2007.76.365

Anisimov, A. P., Lindler, L. E., \& Pier, G. B. (2004). Intraspecific diversity of Yersinia pestis. Clinical Microbiology Reviews, 17, 434-464.

Araújo, M. B., Pearson, R. G., \& Rahbek, C. (2005). Equilibrium of species' distributions with climate. Ecography, 28, 693-695. https://doi. org/10.1111/j.2005.0906-7590.04253.x

Ayyadurai, S., Houhamdi, L., Lepidi, H., Nappez, C., Raoult, D., \& Drancourt, M. (2008). Long-term persistence of virulent Yersinia pestis in soil. Microbiology, 154, 2865-2871. https://doi.org/10.1099/ mic.0.2007/016154-0

Bacot, A. (1914). Lxix. A study of the bionomics of the common rat fleas and other species associated with human habitations, with special reference to the influence of temperature and humidity at various periods of the life history of the insect. The Journal of Hygiene, 13, 447.

Baltazard, M., Karimi, Y., Eftekhari, M., Chamsa, M., \& Mollaret, H. (1964). Interepizootic conservation of plague in its inveterate foci: Working hypotheses. Tech. Rep., Army Biological Laboratories.
Barbieri, R., Texier, G., Keller, C., \& Drancourt, M. (2020). Soil salinity and aridity specify plague foci in the United States of America. Scientific Reports, 10, 1-9. https://doi.org/10.1038/s41598-02063211-4

Becker, D. J., Seifert, S. N., \& Carlson, C. J. (2020). Beyond infection: Integrating competence into reservoir host prediction. Trends in Ecology and Evolution, 35, 1062-1065. https://doi.org/10.1016/ j.tree.2020.08.014

Ben Ari, T., Gershunov, A., Gage, K. L., Snäll, T., Ettestad, P., Kausrud, K. L., \& Stenseth, N. C. (2008). Human plague in the USA: The importance of regional and local climate. Biology Letters, 4(6), 737740. https://doi.org/10.1098/rsbl.2008.0363

Benavides-Montaño, J. A., \& Vadyvaloo, V. (2017). Yersinia pestis resists predation by Acanthamoeba castellanii and exhibits prolonged intracellular survival. Applied and Environmental Microbiology, 83. https://doi.org/10.1128/AEM.00593-17

Bevins, S. N., Baroch, J. A., Nolte, D. L., Zhang, M., \& He, H. (2012). Yersinia pestis: Examining wildlife plague surveillance in China and the USA. Integrative Zoology, 7, 99-109. https://doi.org/ 10.1111/j.1749-4877.2011.00277.x

Bhatt, S., Gething, P. W., Brady, O. J., Messina, J. P., Farlow, A. W., Moyes, C. L., Drake, J. M., Brownstein, J. S., Hoen, A. G., Sankoh, O., Myers, M. F., George, D. B., Jaenisch, T., Wint, G. R. W., Simmons, C. P., Scott, T. W., Farrar, J. J., \& Hay, S. I. (2013). The global distribution and burden of dengue. Nature, 496, 504-507. https://doi. org/10.1038/nature12060

Blackburn, J. K., McNyset, K. M., Curtis, A., \& Hugh-Jones, M. E. (2007). Modeling the geographic distribution of Bacillus anthracis, the causative agent of anthrax disease, for the contiguous United States using predictive ecologic niche modeling. The American Journal of Tropical Medicine and Hygiene, 77, 1103-1110. https://doi. org/10.4269/ajtmh.2007.77.1103

Boegler, K. A., Graham, C. B., Montenieri, J. A., MacMillan, K., Holmes, J. L., Petersen, J. M., Gage, K. L., \& Eisen, R. J. (2012). Evaluation of the infectiousness to mice of soil contaminated with Yersinia pestisinfected blood. Vector-Borne and Zoonotic Diseases, 12, 948-952.

Bosio, C. F., Jarrett, C. O., Scott, D. P., Fintzi, J., \& Hinnebusch, B. J. (2020). Comparison of the transmission efficiency and plague progression dynamics associated with two mechanisms by which fleas transmit Yersinia pestis. PLoS Path, 16, e1009092. https://doi.org/10.1371/ journal.ppat.1009092

Bramanti, B., Dean, K. R., Walløe, L., \& Chr. Stenseth, N. (2019). The third plague pandemic in Europe. Proceedings of the Royal Society B: Biological Sciences, 286(1901), 20182429-https://doi.org/10.1098/ rspb.2018.2429

Brickner-Braun, I., Zucker-Milwerger, D., Braun, A., Turner, J. S., Pinshow, B., \& Berliner, P. (2014). Ventilation of multi-entranced rodent burrows by boundary layer eddies. Journal of Experimental Biology, 217, 4141-4148. https://doi.org/10.1242/jeb.114231

Brown, H. E., Ettestad, P., Reynolds, P. J., Brown, T. L., Hatton, E. S., Holmes, J. L., Glass, G. E., Gage, K. L., \& Eisen, R. J. (2010). Climatic predictors of the intra-and inter-annual distributions of plague cases in New Mexico based on 29 years of animal-based surveillance data. The American Journal of Tropical Medicine and Hygiene, 82, 95-102. https://doi.org/10.4269/ajtmh.2010.09-0247

Brown, H. E., Levy, C. E., Enscore, R. E., Schriefer, M. E., DeLiberto, T. J., Gage, K. L., \& Eisen, R. J. (2011). Annual seroprevalence of Yersinia pestis in coyotes as predictors of interannual variation in reports of human plague cases in Arizona, United States. Vector-borne and Zoonotic Diseases, 11, 1439-1446.

Buck, J., \& Perkins, S. (2018). Study scale determines whether wildlife loss protects against or promotes tick-borne disease. Proceedings of the Royal Society B: Biological Sciences, 285, 20180218. https://doi. org/10.1098/rspb.2018.0218 
Caminade, C., McIntyre, K. M., \& Jones, A. E. (2019). Impact of recent and future climate change on vector-borne diseases. Annals of the New York Academy of Sciences, 1436, 157.

Campbell, S. B., Nelson, C. A., Hinckley, A. F., \& Kugeler, K. J. (2019). Animal exposure and human plague, United States, 1970-2017. Emerging Infectious Diseases, 25, 2270. https://doi.org/10.3201/ eid2512.191081

Carleton, T. A., \& Hsiang, S. M. (2016). Social and economic impacts of climate. Science, 353. https://doi.org/10.1126/science.aad9837

Carlson, C. J. (2020). embarcadero: Species distribution modelling with Bayesian additive regression trees in R. Methods in Ecology and Evolution, 11, 850-858.

Carlson, C. J., Gregory, F. A., Cory, M., Christopher, H. T., Casey, M. Z., Evan, A. E., Kevin, O., Noam, R., \& Shweta, B. (2020). Climate change will drive novel cross-species viral transmission. bioRxiv.

Carlson, C. J., Getz, W. M., Kausrud, K. L., Cizauskas, C. A., Blackburn, J. K., Bustos, F. A., Carrillo, R. C., Ryan Easterday, W., Ganz, H. H., Kamath, P. L., Økstad, O. A., Turner, W. C., Kolstø, A.-B., \& Stenseth, N. C. (2018). Spores and soil from six sides: Interdisciplinarity and the environmental biology of anthrax (Bacillus anthracis). Biological Reviews, 93, 1813-1831.

Carlson, C. J., Kracalik, I. T., Ross, N., Alexander, K. A., Hugh-Jones, M. E., Fegan, M., Elkin, B. T., Epp, T., Shury, T. K., Zhang, W., Bagirova, M., Getz, W. M., \& Blackburn, J. K. (2019). The global distribution of Bacillus anthracis and associated anthrax risk to humans, livestock and wildlife. Nature Microbiology, 4, 1337-1343.

Chandler, J. C., Baeten, L. A., Griffin, D. L., Gidlewski, T., DeLiberto, T. J., Petersen, J. M., Pappert, R., Young, J. W., \& Bevins, S. N. (2018). A bead-based flow cytometric assay for monitoring Yersinia pestis exposure in wildlife. Journal of Clinical Microbiology, 56. https://doi. org/10.1128/JCM.00273-18

Chipman, H. A., George, E. I., \& McCulloch, R. E. (2010). Bart: Bayesian additive regression trees. The Annals of Applied Statistics, 4, 266298. https://doi.org/10.1214/09-AOAS285

Chu, C. M. (2000). Laboratory manual of plague diagnostic tests. Center for Disease Control and Prevention. U.S. Centers for Disease Control and Prevention.

Colman, R. E., R. Jory, B., Joseph, D. B., Chris, R., Adina, D., Jason, W. S., Paul, K., Sharon, K. C., \& David, M. W. (2021). No evidence for enzootic plague within black-tailed prairie dog (Cynomys ludovicianus) populations. Integrative Zoology.

Danforth, M., Tucker, J., \& Novak, M. (2018). The deer mouse (Peromyscus maniculatus) as an enzootic reservoir of plague in California. EcoHealth, 15, 566-576. https://doi.org/10.1007/s1039 3-018-1337-2

Di Luzio, M., Johnson, G. L., Daly, C., Eischeid, J. K., \& Arnold, J. G. (2008). Constructing retrospective gridded daily precipitation and temperature datasets for the conterminous United States. Journal of Applied Meteorology and Climatology, 47, 475-497. https://doi. org/10.1175/2007JAMC1356.1

Dobrowski, S.Z., Thorne, J. H., Greenberg, J. A., Safford, H. D., Mynsberge, A. R., Crimmins, S. M., \& Swanson, A. K. (2011). Modeling plant ranges over 75 years of climate change in California, USA: Temporal transferability and species traits. Ecological Monographs, 81, 241257. https://doi.org/10.1890/10-1325.1

Dorie, V. (2020). dbarts. R package.

Downs, C. J., Pinshow, B., Khokhlova, I. S., \& Krasnov, B. R. (2015). Flea fitness is reduced by high fractional concentrations of $\mathrm{CO}_{2}$ that simulate levels found in their hosts' burrows. Journal of Experimental Biology, 218, 3596-3603. https://doi.org/10.1242/ jeb.122812

Ebi, K. L., Ogden, N. H., Semenza, J. C., \& Woodward, A. (2017). Detecting and attributing health burdens to climate change. Environmental Health Perspectives, 125, 085004. https://doi.org/10.1289/EHP1509

Eisen, R. J., Borchert, J. N., Mpanga, J. T., Atiku, L. A., MacMillan, K., Boegler, K. A., Montenieri, J. A., Monaghan, A., \& Gage, K. L. (2012).
Flea diversity as an element for persistence of plague bacteria in an East African plague focus. PLoS One, 7, e35598. https://doi. org/10.1371/journal.pone.0035598

Eisen, R. J., Eisen, L., \& Gage, K. L. (2009). Studies of vector competency and efficiency of North American fleas for Yersinia pestis: State of the field and future research needs. Journal of Medical Entomology, 46, 737-744.

Eisen, R. J., Enscore, R. E., Biggerstaff, B. J., Reynolds, P. J., Ettestad, P., Brown, T., Pape, J., Tanda, D., Levy, C. E., Engelthaler, D. M., Cheek, J., Bueno, R., Targhetta, J., Montenieri, J. A., \& Gage, K. L. (2007). Human plague in the southwestern United States, 1957-2004: Spatial models of elevated risk of human exposure to Yersinia pestis. Journal of Medical Entomology, 44, 530-537.

Eisen, R. J., Petersen, J. M., Higgins, C. L., Wong, D., Levy, C. E., Mead, P. S., Schriefer, M. E., Griffith, K. S., Gage, K. L., \& Ben Beard, C. (2008). Persistence of Yersinia pestis in soil under natural conditions. Emerging Infectious Diseases, 14, 941.

ElI, S. R. (1985). Iron in two seventeenth-century plague epidemics. The Journal of Interdisciplinary History, 15, 445-457. https://doi. org/10.2307/204140

Escobar, L. E., \& Craft, M. E. (2016). Advances and limitations of disease biogeography using ecological niche modeling. Frontiers in Microbiology, 7, 1174. https://doi.org/10.3389/fmicb.2016.01174

Estrada-Pena, A., Ostfeld, R. S., Peterson, A. T., Poulin, R., \& de la Fuente, J. (2014). Effects of environmental change on zoonotic disease risk: An ecological primer. Trends in Parasitology, 30, 205-214. https:// doi.org/10.1016/j.pt.2014.02.003

Fowler, J. M., Wulff, C. R., Straley, S. C., \& Brubaker, R. R. (2009). Growth of calciumblind mutants of Yersinia pestis at $37 \mathrm{C}$ in permissive Ca2+-deficient environments. Microbiology, 155, 2509.

Frigessi, A., Holden, M., Marshall, C., Viljugrein, H., Stenseth, N. C., Holden, L., Ageyev, V., \& Klassovskiy, N. L. (2005). Bayesian population dynamics of interacting species: Great gerbils and fleas in Kazakhstan. Biometrics, 61, 230-238. https://doi. org/10.1111/j.0006-341X.2005.030536.x

Gage, K. L., Montenieri, J. A., \& Thomas, R. E.. (1994). The role of predators in the ecology, epidemiology, and surveillance of plague in the United States. In Proceedings of the Vertebrate Pest Conference, vol. 16, no. 16.

Gallien, L., Douzet, R., Pratte, S., Zimmermann, N. E., \& Thuiller, W. (2012). Invasive species distribution models-How violating the equilibrium assumption can create new insights. Global Ecology and Biogeography, 21, 1126-1136. https://doi. org/10.1111/j.1466-8238.2012.00768.x

Gibb, R., Redding, D. W., Chin, K. Q., Donnelly, C. A., Blackburn, T. M., Newbold, T., \& Jones, K. E. (2020). Zoonotic host diversity increases in human-dominated ecosystems. Nature, 584, 398-402. https://doi.org/10.1038/s41586-020-2562-8

Giles, J., Peterson, A. T., \& Almeida, A. (2011). Ecology and geography of plague transmission areas in northeastern Brazil. PLoS Neglected Tropical Diseases, 5, e925. https://doi.org/10.1371/journ al.pntd.0000925

Giorgi, E., Kreppel, K., Diggle, P. J., Caminade, C., Ratsitorahina, M., Rajerison, M., \& Baylis, M. (2016). Modeling of spatio-temporal variation in plague incidence in Madagascar from 1980 to 2007. Spatial and Spatio-Temporal Epidemiology, 19, 125-135. https://doi. org/10.1016/j.sste.2016.10.001

Halliday, F. W., \& Rohr, J. R. (2019). Measuring the shape of the biodiversity-disease relationship across systems reveals new findings and key gaps. Nature Communications, 10, 1-10. https://doi. org/10.1038/s41467-019-13049-w

Hay, S. I., Battle, K. E., Pigott, D. M., Smith, D. L., Moyes, C. L., Bhatt, S., Brownstein, J. S., Collier, N., Myers, M. F., George, D. B., \& Gething, P. W. (2013). Global mapping of infectious disease. Philosophical Transactions of the Royal Society B: Biological Sciences, 368, 20120250. https://doi.org/10.1098/rstb.2012.0250 
Hengl, T., Mendes de Jesus, J., Heuvelink, G. B. M., Ruiperez Gonzalez, M., Kilibarda, M., Blagotić, A., Shangguan, W., Wright, M. N., Geng, X., Bauer-Marschallinger, B., Guevara, M. A., Vargas, R., MacMillan, R. A., Batjes, N. H., Leenaars, J. G. B., Ribeiro, E., Wheeler, I., Mantel, S., \& Kempen, B. (2017). Soilgrids250m: Global gridded soil information based on machine learning. PLoS One, 12, e0169748. https://doi.org/10.1371/journal.pone.0169748

Hiemstra, P., Hiemstra, M. P. (2013). automap. R package.

Hieronimo, P., Meliyo, J., Gulinck, H., Kimaro, D. N., Mulungu, L. S., Kihupi, N. I., Msanya, B. M., Leirs, H., \& Deckers, J. A. (2014). Integrating land cover and terrain characteristics to explain plague risks in Western Usambara Mountains, Tanzania: A geospatial approach. Tanzania Journal of Health Research, 16. https://doi.org/10.4314/ thrb.v16i3.7

Hollister, J., \& Shah, T. (2017). elevatr: Access elevation data from various APIs. R Package.

Holt, A. C., Salkeld, D. J., Fritz, C. L., Tucker, J. R., \& Gong, P. (2009). Spatial analysis of plague in California: Niche modeling predictions of the current distribution and potential response to climate change. International Journal of Health Geographics, 8, 38. https:// doi.org/10.1186/1476-072X-8-38

Hooker-Romero, D., Mettert, E., Schwiesow, L., Balderas, D., Alvarez, P. A., Kicin, A., Gonzalez, A. L., Plano, G. V., Kiley, P. J., \& Auerbuch, V. (2019). Iron availability and oxygen tension regulate the Yersinia Ysc type III secretion system to enable disseminated infection. PLoS Path, 15, e1008001. https://doi.org/10.1371/journ al.ppat.1008001

Johnson, P. T., Preston, D. L., Hoverman, J. T., \& Richgels, K. L. (2013). Biodiversity decreases disease through predictable changes in host community competence. Nature, 494, 230-233. https://doi. org $/ 10.1038 /$ nature11883

Jones, S. D., Atshabar, B., Schmid, B. V., Zuk, M., Amramina, A., \& Stenseth, N. C. (2019). Living with plague: Lessons from the Soviet Union's antiplague system. Proceedings of the National Academy of Sciences of the United States of America, 116, 9155-9163. https:// doi.org/10.1073/pnas.1817339116

Karimi, Y. (1963). Natural preservation of plague in soil. Bulletin de la Societe de Pathologie Exotique et de ses Filiales, 56, 1183-1186.

Kaul, R. B., Evans, M. V., Murdock, C. C., \& Drake, J. M. (2018). Spatiotemporal spillover risk of yellow fever in Brazil. Parasites and Vectors, 11, 488. https://doi.org/10.1186/s13071-018-3063-6

Kraemer, M. U. G., Hay, S. I., Pigott, D. M., Smith, D. L., Wint, G. R. W., \& Golding, N. (2016). Progress and challenges in infectious disease cartography. Trends in Parasitology, 32, 19-29. https://doi. org/10.1016/j.pt.2015.09.006

Kraemer, M. U. G., Reiner, R. C., Brady, O. J., Messina, J. P., Gilbert, M., Pigott, D. M., Yi, D., Johnson, K., Earl, L., Marczak, L. B., Shirude, S., Davis Weaver, N., Bisanzio, D., Perkins, T. A., Lai, S., Lu, X., Jones, P., Coelho, G. E., Carvalho, R. G., ... Golding, N. (2019). Past and future spread of the arbovirus vectors Aedes aegypti and Aedes albopictus. Nature Microbiology, 4, 854-863. https://doi.org/10.1038/s4156 4-019-0376-y

Krasnov, B. R., Shenbrot, G. I., Khokhlova, I. S., \& Poulin, R. (2006). Is abundance a species attribute? An Example with Haematophagous Ectoparasites. Oecologia, 150, 132-140. https://doi.org/10.1007/ s00442-006-0498-9

Kulkarni, M. A., Desrochers, R. E., Kajeguka, D. C., Kaaya, R. D., Tomayer, A., Kweka, E. J., Protopopoff, N., \& Mosha, F. W. (2016). 10 years of environmental change on the slopes of Mount Kilimanjaro and its associated shift in malaria vector distributions. Frontiers in Public Health, 4, 281. https://doi.org/10.3389/ fpubh.2016.00281

Kutyrev, V. V., \& A. Y. Popova (Eds.) (2016). The inventory of epidemic and epizootic manifestations of plague on the territory of the Former Soviet Union from 1876 to 2016. Saratov State University.
Lemon, A., Cherzan, N., \& Vadyvaloo, V. (2020). Influence of temperature on development of Yersinia pestis foregut blockage in Xenopsylla cheopis (Siphonaptera: Pulicidae) and Oropsylla montana (Siphonaptera: Ceratophyllidae). Journal of Medical Entomology, 57, 1997-2007.

Liccioli, S., Stephens, T., Wilson, S. C., McPherson, J. M., Keating, L. M., Antonation, K. S., Bollinger, T. K., Corbett, C. R., Gummer, D. L., Lindsay, L. R., Galloway, T. D., Shury, T. K., \& Moehrenschlager, A. (2020). Enzootic maintenance of sylvatic plague in Canada's threatened black-tailed prairie dog ecosystem. Ecosphere, 11. https://doi. org/10.1002/ecs2.3138

Limmathurotsakul, D., Golding, N., Dance, D. A. B., Messina, J. P., Pigott, D. M., Moyes, C. L., Rolim, D. B., Bertherat, E., Day, N. P. J., Peacock, S. J., \& Hay, S. I. (2016). Predicted global distribution of Burkholderia pseudomallei and burden of melioidosis. Nature Microbiology, 1, 15008. https://doi.org/10.1038/nmicrobiol.2015.8

Link, V. B. (1955). A history of plague in the United States of America. 392. US Government Printing Office.

Linné Kausrud, K., Viljugrein, H., Frigessi, A., Begon, M., Davis, S., Leirs, H., Dubyanskiy, V., \& Stenseth, N. C. (2007). Climatically driven synchrony of gerbil populations allows large-scale plague outbreaks. Proceedings of the Royal Society B: Biological Sciences, 274, 1963-1969. https://doi.org/10.1098/rspb.2007.0568

Loh, E. H., Zambrana-Torrelio, C., Olival, K. J., Bogich, T. L., Johnson, C. K., Mazet, J. A. K., Karesh, W., \& Daszak, P. (2015). Targeting transmission pathways for emerging zoonotic disease surveillance and control. Vector-Borne and Zoonotic Diseases, 15, 432-437. https://doi.org/10.1089/vbz.2013.1563

Lowell, J. L., Antolin, M. F., Andersen, G. L., Ping, H. U., Stokowski, R. P., \& Gage, K. L. (2015). Single-nucleotide polymorphisms reveal spatial diversity among clones of Yersinia pestis during plague outbreaks in Colorado and the western United States. Vector-Borne and Zoonotic Diseases, 15, 291-302.

Luis, A. D., Kuenzi, A. J., \& Mills, J. N. (2018). Species diversity concurrently dilutes and amplifies transmission in a zoonotic hostpathogen system through competing mechanisms. Proceedings of the National Academy of Sciences of the United States of America, 115, 7979-7984. https://doi.org/10.1073/pnas.1807106115

Maher, S. P., Ellis, C., Gage, K. L., Enscore, R. E., \& Peterson, A. T. (2010). Range-wide determinants of plague distribution in North America. The American Journal of Tropical Medicine and Hygiene, 83, 736-742. https://doi.org/10.4269/ajtmh.2010.10-0042

Mahmoudi, A., Kryštufek, B., Sludsky, A., Schmid, B. V., De almeida, A. M. P., Lei, X. U., Ramasindrazana, B., Bertherat, E., Yeszhanov, A., Stenseth, N. C., \& Mostafavi, E. (2020). Plague reservoir species throughout the world. Integrative Zoology. https://doi. org/10.1111/1749-4877.12511

Malek, M. A., Bitam, I., \& Drancourt, M. (2016). Plague in Arab Maghreb, 1940-2015: A review. Frontiers in Public Health, 4, 112. https://doi. org/10.3389/fpubh.2016.00112

Malek, M. A., Bitam, I., Levasseur, A., Terras, J., Gaudart, J., Azza, S., Flaudrops, C., Robert, C., Raoult, D., \& Drancourt, M. (2017). Yersinia pestis halotolerance illuminates plague reservoirs. Scientific Reports, 7, 1-10. https://doi.org/10.1038/srep40022

Markman, D. W., Antolin, M. F., Bowen, R. A., Wheat, W. H., Woods, M., Gonzalez-Juarrero, M., \& Jackson, M. (2018). Yersinia pestis survival and replication in potential ameba reservoir. Emerging Infectious Diseases, 24, 294.

Miller, E., \& Huppert, A. (2013). The effects of host diversity on vectorborne disease: The conditions under which diversity will amplify or dilute the disease risk. PLoS One, 8, e80279. https://doi. org/10.1371/journal.pone.0080279

Moore, S. M., Monaghan, A., Borchert, J. N., Mpanga, J. T., Atiku, L. A., Boegler, K. A., Montenieri, J., MacMillan, K., Gage, K. L., \& Eisen, R. J. (2015). Seasonal fluctuations of small mammal and flea 
communities in a Ugandan plague focus: Evidence to implicate Arvicanthis niloticus and Crocidura spp. as key hosts in Yersinia pestis transmission. Parasites and Vectors, 8, 1-15. https://doi. org/10.1186/s13071-014-0616-1

Mordecai, E. A., Caldwell, J. M., Grossman, M. K., Lippi, C. A., Johnson, L. R., Neira, M., Rohr, J. R., Ryan, S. J., Savage, V., Shocket, M. S., Sippy, R., Stewart Ibarra, A. M., Thomas, M. B., \& Villena, O. (2019). Thermal biology of mosquito-borne disease. Ecology Letters, 22 1690-1708. https://doi.org/10.1111/ele.13335

Morelli, G., Song, Y., Mazzoni, C. J., Eppinger, M., Roumagnac, P., Wagner, D. M., Feldkamp, M., Kusecek, B., Vogler, A. J., Li, Y., Cui, Y., Thomson, N. R., Jombart, T., Leblois, R., Lichtner, P., Rahalison, L., Petersen, J. M., Balloux, F., Keim, P., ... Achtman, M. (2010). Yersinia pestis genome sequencing identifies patterns of global phylogenetic diversity. Nature Genetics, 42, 1140-1143. https://doi. org/10.1038/ng.705

Nakazawa, Y., Williams, R., Peterson, A. T., Mead, P., Staples, E., \& Gage, K. L. (2007). Climate change effects on plague and tularemia in the United States. Vector-borne and Zoonotic Diseases, 7, 529-540. https://doi.org/10.1089/vbz.2007.0125

Neerinckx, S., Bertherat, E., \& Leirs, H. (2010). Human plague occurrences in Africa: An overview from 1877 to 2008. Transactions of the Royal Society of Tropical Medicine and Hygiene, 104, 97-103. https://doi.org/10.1016/j.trstmh.2009.07.028

Neerinckx, S. B., Peterson, A. T., Gulinck, H., Deckers, J., \& Leirs, H. (2008). Geographic distribution and ecological niche of plague in sub-Saharan Africa. International Journal of Health Geographics, 7, 54. https://doi.org/10.1186/1476-072X-7-54

Nilsson, P., Ravinet, M., Cui, Y., Berg, P., Zhang, Y., Guo, R., Luo, T., Song, Y., Trucchi, E., Hoff, S., Lv, R., Schmid, B. V., Easterday, W. R., Jakobsen, K. S., Stenseth, N. C., \& Sissel Jentoft, R. Y. (2021). Polygenic plague resistance in the great gerbil uncovered by population sequencing. Authorea Preprints.

Norberg, A., Abrego, N., Blanchet, F. G., Adler, F. R., Anderson, B. J., Anttila, J., Araújo, M. B., Dallas, T., Dunson, D., Elith, J., Foster, S. D., Fox, R., Franklin, J., Godsoe, W., Guisan, A., O'Hara, B., Hill, N. A., Holt, R. D., Hui, F. K. C., ... Ovaskainen, O. (2019). A comprehensive evaluation of predictive performance of 33 species distribution models at species and community levels. Ecological Monographs, e01370. https://doi.org/10.1002/ecm.1370

Parmenter, R. R., Yadav, E. P., Parmenter, C. A., Ettestad, P., \& Gage, K. L. (1999). Incidence of plague associated with increased winterspring precipitation in New Mexico. The American Journal of Tropical Medicine and Hygiene, 61, 814-821. https://doi.org/10.4269/ ajtmh.1999.61.814

Peterson, A. T., Gulinck, H., Deckers, J., Kimaro, D., Neerinckx, S., \& Leirs, H. (2010). Predicting potential risk areas of human plague for the Western Usambara Mountains, Lushoto District, Tanzania. The American Journal of Tropical Medicine and Hygiene, 82, 492-500. https://doi.org/10.4269/ajtmh.2010.09-0426

Peterson, A. T., Martínez-Campos, C., Nakazawa, Y., \& Martínez-Meyer, E. (2005). Time-specific ecological niche modeling predicts spatial dynamics of vector insects and human dengue cases. Transactions of the Royal Society of Tropical Medicine and Hygiene, 99(9), 647-655. https://doi.org/10.1016/j.trstmh.2005.02.004

Pigott, D. M., Golding, N., Mylne, A., Huang, Z., Henry, A. J., Weiss, D. J., Brady, O. J., Kraemer, M. U. G., Smith, D. L., Moyes, C. L., Bhatt, S., Gething, P. W., Horby, P. W., Bogoch, I. I., Brownstein, J. S., Mekaru, S. R., Tatem, A. J., Khan, K., \& Hay, S. I. (2014). Mapping the zoonotic niche of Ebola virus disease in Africa. eLife, 3, e04395. https://doi. org/10.7554/eLife.04395

Poje, J. E., Rocke, T. E., \& Samuel, M. D. (2020). Impacts of environmental conditions on fleas in black-tailed prairie dog burrows. Journal of Vector Ecology, 45, 356-365. https://doi.org/10.1111/ jvec.12405

Qian, Q., Zhao, J., Fang, L., Zhou, H., Zhang, W., Wei, L., Yang, H., Yin, W., Cao, W., \& Li, Q. (2014). Mapping risk of plague in Qinghai-Tibetan plateau, China. BMC Infectious Diseases, 14, 382. https://doi. org/10.1186/1471-2334-14-382

Quenee, L. E., Hermanas, T. M., Ciletti, N., Louvel, H., Miller, N. C., Elli, D., Blaylock, B., Mitchell, A., Schroeder, J., Krausz, T., Kanabrocki, J., \& Schneewind, O. (2012). Hereditary hemochromatosis restores the virulence of plague vaccine strains. The Journal of Infectious Diseases, 206, 1050-1058. https://doi.org/10.1093/infdis/jis433

Ramesh, V., Gopalakrishna, T., Barve, S., \& Melnick, D. J. (2017). IUCN greatly underestimates threat levels of endemic birds in the Western Ghats. Biological Conservation, 210, 205-221. https://doi. org/10.1016/j.biocon.2017.03.019

Randremanana, R., Andrianaivoarimanana, V., Nikolay, B., Ramasindrazana, B., Paireau, J., ten Bosch, Q. A., Rakotondramanga, J. M., Rahajandraibe, S., Rahelinirina, S., Rakotomanana, F., Rakotoarimanana, F. M., Randriamampionona, L. B., Razafimbia, V., De Dieu Randria, M. J., Raberahona, M., Mikaty, G., Le Guern, A.-S., Rakotonjanabelo, L. A., Ndiaye, C. F., ... Rajerison, M. (2019). Epidemiological characteristics of an urban plague epidemic in Madagascar, August-November, 2017: An outbreak report. The Lancet Infectious Diseases, 19, 537-545. https://doi.org/10.1016/ S1473-3099(18)30730-8

Reijniers, J., Begon, M., Ageyev, V. S., \& Leirs, H. (2014). Plague epizootic cycles in Central Asia. Biology Letters, 10, 20140302.

Richards, R. L., Cleveland, C. A., Hall, R. J., Tchindebet Ouakou, P., Park, A. W., Ruiz-Tiben, E., Weiss, A., Yabsley, M. J., \& Ezenwa, V. O. (2020). Identifying correlates of Guinea worm (Dracunculus medinensis) infection in domestic dog populations. PLOS Neglected Tropical Diseases, 14, e0008620. https://doi.org/10.1371/journal. pntd.0008620

Rocklöv, J., \& Dubrow, R. (2020). Climate change: An enduring challenge for vector-borne disease prevention and control. Nature Immunology, 21, 479-483. https://doi.org/10.1038/s41590-020-0648-y

Rohr, J. R., Civitello, D. J., Halliday, F. W., Hudson, P. J., Lafferty, K. D., Wood, C. L., \& Mordecai, E. A. (2020). Towards common ground in the biodiversity-disease debate. Nature Ecology and Evolution, 4, 24-33. https://doi.org/10.1038/s41559-019-1060-6

Ross, N. (2020). fasterize: Fast polygon to raster conversion, version 1.0.0. $R$ package.

Ryan, S. J., Carlson, C. J., Mordecai, E. A., \& Johnson, L. R. (2019). Global expansion and redistribution of Aedes-borne virus transmission risk with climate change. PLoS Neglected Tropical Diseases, 13, e0007213. https://doi.org/10.1371/journal.pntd.0007213

Samia, N. I., Kausrud, K. L., Heesterbeek, H., Ageyev, V., Begon, M., Chan, K.-S., \& Stenseth, N. C. (2011). Dynamics of the plague-wildlifehuman system in Central Asia are controlled by two epidemiological thresholds. Proceedings of the National Academy of Sciences of the United States of America, 108, 14527-14532. https://doi. org/10.1073/pnas.1015946108

Schmid, B. V., Büntgen, U., Easterday, W. R., Ginzler, C., Walløe, L., Bramanti, B., \& Stenseth, N. C. (2015). Climate-driven introduction of the Black Death and successive plague reintroductions into Europe. Proceedings of the National Academy of Sciences of the United States of America, 112, 3020-3025. https://doi.org/10.1073/ pnas.1412887112

Schmidt, J. P., Park, A. W., Kramer, A. M., Han, B. A., Alexander, L. W., \& Drake, J. M. (2017). Spatiotemporal fluctuations and triggers of Ebola virus spillover. Emerging Infectious Diseases, 23, 415. https:// doi.org/10.3201/eid2303.160101

Schmidt, K. A., \& Ostfeld, R. S. (2001). Biodiversity and the dilution effect in disease ecology. Ecology, 82, 609-619.

Schneewind, O. (2016). Classic spotlight: studies on the low-calcium response of Yersinia pestis reveal the secrets of plague pathogenesis. Journal of Bacteriology, 198, 2018. https://doi.org/10.1128/JB.00358-16

Schneider, M. C., Najera, P., Aldighieri, S., Galan, D. I., Bertherat, E., Ruiz, A., Dumit, E., Gabastou, J. M., \& Espinal, M. A. (2014). Where does human plague still persist in Latin America? PLoS Neglected Tropical Diseases, 8, e2680. https://doi.org/10.1371/journal.pntd.0002680 
Schotthoefer, A. M., Bearden, S. W., Holmes, J. L., Vetter, S. M. Montenieri, J. A., Williams, S. K., Graham, C. B., Woods, M. E., Eisen, R. J., \& Gage, K. L. (2011). Effects of temperature on the transmission of Yersinia pestis by the flea, Xenopsylla cheopis, in the late phase period. Parasites and Vectors, 4, 1-11.

Seal, S. (1960). Epidemiological studies of plague in India: 1. The present position. Bulletin of the World Health Organization, 23, 283.

Shearer, F. M., Longbottom, J., Browne, A. J., Pigott, D. M., Brady, O. J., Kraemer, M. U. G., Marinho, F., Yactayo, S., de Araújo, V. E. M., da Nóbrega, A. A., Fullman, N., Ray, S. E., Mosser, J. F., Stanaway, J. D., Lim, S. S., Reiner, R. C., Moyes, C. L., Hay, S. I., \& Golding, N. (2018). Existing and potential infection risk zones of yellow fever world wide: A modelling analysis. The Lancet Global Health, 6, e270-e278. https://doi.org/10.1016/S2214-109X(18)30024-X

Smith, D. B., Cannon, W. F., Woodruff, L. G., Solano, F. E., \& Karl, J. (2013). Geochemical and mineralogical data for soils of the conterminous United States. Tech. Rep., US Geological Survey.

Smith, D. B., Cannon, W. F., \& Woodruff, L. G. (2011). A national-scale geochemical and mineralogical survey of soils of the conterminous United States. Applied Geochemistry, 26, S250-S255. https://doi. org/10.1016/j.apgeochem.2011.03.116

Stenseth, N. C., Atshabar, B. B., Begon, M., Belmain, S. R., Bertherat, E., Carniel, E., Gage, K. L., Leirs, H., \& Rahalison, L. (2008). Plague: Past, present, and future. PLoS Med, 5, e3.

Stenseth, N. C., Samia, N. I., Viljugrein, H., Kausrud, K. L., Begon, M., Davis, S., Leirs, H., Dubyanskiy, V. M., Esper, J., Ageyev, V. S., Klassovskiy, N. L., Pole, S. B., \& Chan, K.-S. (2006). Plague dynamics are driven by climate variation. Proceedings of the National Academy of Sciences of the United States of America, 103, 13110-13115. https://doi.org/10.1073/pnas.0602447103

Sun, Z., Xu, L., Schmid, B. V., Dean, K. R., Zhang, Z., Xie, Y., Fang, X., Wang, S., Liu, Q., Lyu, B., Wan, X., Xu, J., Stenseth, N. C., \& Xu, B. (2019). Human plague system associated with rodent diversity and other environmental factors. Royal Society Open Science, 6, 190216. https://doi.org/10.1098/rsos.190216

Trisos, C. H., Merow, C., \& Pigot, A. L. (2020). The projected timing of abrupt ecological disruption from climate change. Nature, 580, 496-501. https://doi.org/10.1038/s41586-020-2189-9
Viana, M., Mancy, R., Biek, R., Cleaveland, S., Cross, P. C., Lloyd-Smith, J. O., \& Haydon, D. T. (2014). Assembling evidence for identifying reservoirs of infection. Trends in Ecology and Evolution, 29, 270-279. https://doi.org/10.1016/j.tree.2014.03.002

Walsh, M., \& Haseeb, M. (2015). Modeling the ecologic niche of plague in sylvan and domestic animal hosts to delineate sources of human exposure in the western United States. PeerJ, 3, e1493. https://doi. org/10.7717/peerj.1493

Warth, J. F. G., Biesdorf, S. M., \& de Souza, C. (2012). Yersinia pseudotuberculosis $\mathrm{O}$ III causes diarrhea in Brazilian cattle. In Advances in Yersinia Research, 107-110. Springer.

Williams, S. K., Schotthoefer, A. M., Montenieri, J. A., Holmes, J. L., Vetter, S. M., Gage, K. L., \& Bearden, S. W. (2013). Effects of low-temperature flea maintenance on the transmission of Yersinia pestis by Oropsylla montana. Vector-Borne and Zoonotic Diseases, 13, 468-478.

Xu, L., Schmid, B. V., Liu, J., Si, X., Stenseth, N. C., \& Zhang, Z. (2015). The trophic responses of two different rodent-vector-plague systems to climate change. Proceedings of the Royal Society B: Biological Sciences, 282, 20141846. https://doi.org/10.1098/rspb.2014.1846

Xu, L., Stige, L. C., Kausrud, K. L., Ben Ari, T., Wang, S., Fang, X., Schmid, B. V., Liu, Q., Stenseth, N. C., \& Zhang, Z. (2014). Wet climate and transportation routes accelerate spread of human plague. Proceedings of the Royal Society B: Biological Sciences, 281, 20133159. https://doi. org/10.1098/rspb.2013.3159

\section{SUPPORTING INFORMATION}

Additional supporting information may be found in the online version of the article at the publisher's website.

How to cite this article: Carlson, C. J., Bevins, S. N., \& Schmid, B. V. (2022). Plague risk in the western United States over seven decades of environmental change. Global Change Biology, 28, 753-769. https://doi.org/10.1111/gcb.15966 